Research Article

\title{
Heat Transfer Simulation and Temperature Rapid Prediction for Trench Laying Cable
}

\author{
Chen-Zhao Fu, ${ }^{1}$ Wen-Rong Si $\mathbb{D},{ }^{1}$ Ke-Ke Fang, ${ }^{2}$ and Jian Yang $\mathbb{D}^{2}$ \\ ${ }^{1}$ State Grid Shanghai Electrical Power Research Institute, Shanghai 200437, China \\ ${ }^{2}$ MOE Key Laboratory of Thermo-Fluid Science and Engineering, Xi'an Jiaotong University, Xi'an 710049, China
}

Correspondence should be addressed to Jian Yang; yangjian81@mail.xjtu.edu.cn

Received 29 July 2021; Accepted 11 October 2021; Published 29 October 2021

Academic Editor: Sardar Muhammad Bilal

Copyright ( $\odot 2021$ Chen-Zhao Fu et al. This is an open access article distributed under the Creative Commons Attribution License, which permits unrestricted use, distribution, and reproduction in any medium, provided the original work is properly cited.

Heat transfer process for trench laying cable is complex. To guarantee safe operation of the cable, it is necessary to predict the temperature and maximum current capacity of trench laying cable rapidly and accurately. Therefore, in this study, an adaptive optimized particle swarm optimization algorithm (LFVPSO) is proposed based on Levy flight algorithm, and it is used to modify the back propagation neural network algorithm (LFVPSO-BPNN). Then, combined with numerical simulations, a network algorithm for temperature prediction of trench laying cable is developed using LFVPSO-BPNN. Finally, the maximum current capacity of four-loop three-phase trench laying cable is calculated using LFVPSO-BPNN together with genetic algorithm (GA\&LFVPSO-BPNN). At first, it is found that the LFVPSO-BPNN algorithm proposed in this study is reliable and accurate to predict the cable maximum temperature for different loops $\left(T_{\max , i}\right)$ in the trench. Furthermore, as compared with other similar algorithms, when LFVPSO-BPNN algorithm is used to predict the temperature of trench laying cable, its computation time would be reduced and the prediction accuracy would be improved as well. Second, it is revealed that the effect of ground air temperature $\left(T_{\text {sur }}\right)$ on the maximum current capacity of trench laying cable $\left(I_{t, \max }\right)$ is remarkable. As $T_{\text {sur }}$ increases, the $I_{t, \text { max }}$ for both flat-type and trefoil-type trench laying cable would significantly decrease. In addition, with the same $T_{\text {sur }}$, the $I_{t, \max }$ for the flat-type trench laying cable are obviously higher.

\section{Introduction}

Due to the urban development and aesthetic demand, the underground cable distributions are prevailing for urban power distribution [1]. Among these distributions, trench laying cables are often used in power plants or transformer substations. As compared with other underground cable laying methods, trench laying is more convenient for cable construction and maintenance, and it can accommodate multiloop cables [2]. The insulation performance of trench laying cable is closely related to its cable core temperature. When the cable core temperature is higher than $363.15 \mathrm{~K}$, the cable insulation aging will be accelerated and cable service life will be greatly shortened [3]. Therefore, to prevent cable overheating and guarantee cable safe operation, it is necessary to predict the temperature rise of trench laying cable rapidly and accurately.
Currently, the temperature prediction and ampacity calculation for underground cable mainly include equivalent thermal circuit method and numerical simulation method. For the equivalent thermal circuit method, it is mainly based on the IEC-60287 standard [4], where the heat transfer process between the cable and environment is equivalent to a thermal circuit for the calculations. This method can predict temperature rise for direct buried cable rapidly and accurately [5]. However, for the trench laying cable, the heat transfer process is much more complex. When the equivalent thermal circuit method is adopted for the calculation, the prediction model would be oversimplified, and it may lead to large prediction errors [6]. For the numerical simulation method, the heat transfer process between the cable and environment is numerically simulated, and the temperature distributions and cable ampacity are obtained based on the finite-element method (FEM) or finite-difference 
method (FDM). For example, Al-Saud et al. [7] numerically studied the temperature variations of direct buried cables using perturbed FEM. They found that the effect of thermal conductivities of soil and backfill material on the cable temperature was remarkable. The effect of cable layout on the temperature distributions and current capacity of trench laying cable was numerically studied by Xiong et al. [8] with FEM. It was found that as compared with regular arrangement, when cables were irregularly arranged in the trench, the cable temperature was higher and its current capacity was lower. While in this work, the radiation heat transfer in the trench was not considered. Liu et al. [9] numerically studied the heat transfer of three flat-type laying cables in a rectangular trench with different Rayleigh numbers. They found that the effect of cable distance on cable heat transfer performance is remarkable. Furthermore, the cable core temperature of shallow trench laying cable was calculated by Anders et al. [10] using thermal circuit method and FEM, respectively. It was found that compared with the thermal circuit method, the computational results obtained using FEM were more accurate, but the computational time of FEM was much longer. The temperature distribution of direct buried cable was numerically studied by Vollaro et al. [11] with FDM, and a calculation correlation of thermal resistance between cable and ground was obtained. It was showed that the prediction results obtained by the FDM were more accurate than those of IEC-60287 standard. Some other thermal modelling studies were also performed by Foteinopoulos et al. [12], Salonitis et al. [13], and Marano et al. [14]. A two-dimensional finite-difference model of the thermal history of parts manufactured in powder bed fusion additive manufacturing processes was presented by Foteinopoulos et al. [12]. In their study, an algorithm for node birth and distance adaptation over time was used, minimizing computational time and memory. Salonitis et al. [13] performed the thermal modelling of the material removal rate and surface roughness for die-sinking electrical discharge machining. In their study, a simple, thermal based model had been developed for the determination of the material removal rate and the average surface roughness achieved as a function of the process parameters, and the model's predictions could agree well with experimental results. The thermal behavior of trench-isolated bipolar transistors was thoroughly investigated by Marano et al. [14]. In their study, a novel strategy to analytically evaluate the temperature field was proposed, which accounted for the heat propagation through the trench and the nonuniform heat flux distribution over the interface between the silicon box surrounded by trench and the underlying substrate. This novel strategy could be employed for an accurate, yet fast evaluation of the thermal resistance of a trench-isolated device as well as of the temperature gradients within the silicon box. Most of these researches showed that as compared with the thermal circuit method, when the heat transfer of trench laying cable was studied with numerical simulations, the accuracy of prediction results would be greatly improved, but its computational time would also be much longer. To solve this problem, artificial intelligence algorithms combined with numerical simulations are recommended for rapid and accurate prediction of cable temperature rise. Recently, for underground cable, artificial intelligence algorithms are mainly focused on the fields of cable laying cost optimization, cable maximum current capacity calculation, and cable temperature prediction. For example, a modified JAYA algorithm was proposed by Ocłoń et al. [15] to optimize the laying cost of $400 \mathrm{kV}$ direct buried cables. It was found that as compared with the traditional particle swarm optimization algorithm (PSO), lower cable laying cost could be obtained with this modified JAYA algorithm. A formula for laying cost calculation of direct buried cable was proposed by Cichy et al. [16], where the costs of labor, material, and operation loss were considered. Combing this formula with genetic algorithm (GA), the optimum cable size and filling size of backfill material were obtained. The maximum current capacity of pipe laying cables, containing 12 cables and 15 pipes, was calculated by Moutassem and Anders [17] with vector immune system algorithm. They found that as compared with numerical simulation using FEM, the calculation time could be greatly reduced with vector immune system algorithm. Combing shuffled frog-leaping algorithm with PSO algorithm, the maximum current capacity of pipe laying cable was calculated by Zarchi et al. [18]. They found that current harmonics would have great influence on maximum cable current capacity. The temperature rise of pipe cable was predicted by Zarchi and Vahidi [19] with Monte Carlo method and Hong point estimate method (HPEM), respectively, and the maximum current capacity of pipe cable was also calculated. It was found that as compared with Monte Carlo method, the HPEM requires fewer input parameters and its calculation cost was lower. Furthermore, a temperature prediction network for parabolic-type buried cable filled with fluidized thermal backfill material was proposed by Fu et al. [20] with radial basis neural network algorithm. Combining this temperature prediction network with genetic algorithm (GA), the optimum cable laying cost was obtained. These studies showed that for recent years, artificial intelligence algorithms used for underground cable were mainly focused on the researches about laying cost optimization for direct buried cable or maximum current capacity calculation for pipe laying cable, while the related researches for temperature prediction of underground cable were few, almost no studies were performed on rapid prediction of temperature rise for trench laying cable.

Therefore, in this study, to predict the temperature rise of trench laying cable rapidly and accurately, an adaptive optimized particle swarm optimization algorithm (LFVPSO) is proposed based on Levy flight algorithm, and it is used to modify the back propagation neural network algorithm (LFVPSO-BPNN). Then combined with numerical simulations, a network algorithm for temperature prediction of trench laying cable is developed using LFVPSO-BPNN. Finally, the maximum current capacity of four-loop three-phase trench laying cable is calculated using LFVPSO-BPNN together with genetic algorithm (GA\&LFVPSO-BPNN). According to the authors' knowledge, almost no such studies were performed yet, and it would be meaningful for temperature rapid prediction and maximum current capacity calculation of trench laying cable. 


\section{Physical Model and Computational Method}

2.1. Physical Model and Geometric Parameters. The physical model and geometric structure for trench laying cable are presented in Figure 1. In this study, since the trench length is much larger than its cross-sectional dimension, the trench laying cable is simplified as a two-dimensional model for the computations. Four-loop three-phase cables are laid in the trench, including flat-type laying model (Figure 1(a)) and trefoil-type laying model (Figure 1(b)). The dimension of the trench is $2 \mathrm{~m}$ (width) $\times 2.2 \mathrm{~m}$ (height). The trench wall is made of concrete, and its thickness is $0.2 \mathrm{~m}$. The inside and outside areas of the trench are filled with air and soil, respectively. It is assumed that the soil temperature far away $(20 \mathrm{~m})$ from the trench bottom is fixed at consistent $\left(T_{\text {soil }}=283.15 \mathrm{~K}\right)$, and the soil far away $(20 \mathrm{~m})$ from trench lateral walls are adiabatic. The top surface of trench is exposed to the environment with temperature of $T_{\text {sur }}$ and the equivalent surface heat transfer coefficient is $h_{f}\left(11 \mathrm{~W} /\left(\mathrm{m}^{2} \cdot \mathrm{K}\right)\right)$. The radiation heat transfer is existed between cable surface and inner surface of trench, where the radiant emissivity on the cable surface is 0.9 , and it is 0.6 on the inner surface of the trench. For flat-type trench laying cable models (Figure 1(a)), the distance between the cable core and trench side wall is $0.12 \mathrm{~m}$. The cable core distance between the upper and lower layer cables is $0.4 \mathrm{~m}$. The distance between the lower layer cable core and trench bottom is $0.15 \mathrm{~m}$. And the cable core distance between two adjacent cables in the same loop is $0.15 \mathrm{~m}$. For trefoil-type trench laying cable models (Figure 1(b)), the distance between the cable core and trench side wall is $0.21 \mathrm{~m}$. The cable core distance between the upper and lower layer cables is $0.5 \mathrm{~m}$. And the distance between the lower layer cable core and trench bottom is $0.15 \mathrm{~m}$. The arrangement for a single-loop three-phase trefoil cables is presented in Figure 1(c), where the cables are in a regular triangle arrangement. To improve the quality of computational mesh near the contact points between cables, the cables are assumed to be stacked with small gaps between each other, where the gap width is $1 \% r_{e}$ [21]. The structure for a single cable $(8.7 / 15 \mathrm{kV}$ YJV $1 \times 400)$ is presented in Figure $1(\mathrm{~d})$. It shows that the cable is mainly composed of cable core, insulation layer, sheath layer, and external layer, and their radii are $r_{c}, r_{\text {ins }}, r_{s}$, and $r_{e}$, respectively. Typical geometrical and physical parameters for the trench laying cable are listed in Tables 1 and 2.

2.2. Governing Equations and Computational Method. In this study, the electromagnetic effect, heat transfer, and air flow are coupled with each other. The computational domain is divided into solid domain and fluid domain for the coupling computations. For solid domain, the governing equations for the heat transfer are as follows:

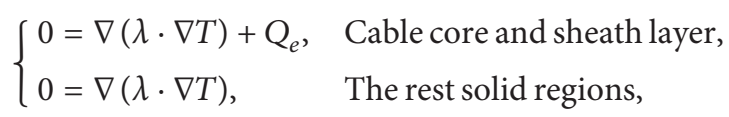

where $T$ is temperature and $\lambda$ is the solid thermal conductivity. The thermal conductivity of soil $\left(\lambda_{\text {soil }}\right)$ changes with temperature, which is defined as follows [23]:

$$
\left\{\begin{array}{l}
\lambda_{\text {soil }}(T)=\lambda_{\text {dry }}+\left(\lambda_{\text {wet }}-\lambda_{\text {dry }}\right) \cdot \exp \left[-a_{1}\left[\frac{\left(T-T_{\text {ref }}\right)}{\left(a_{2} \cdot T_{\text {lim }}\right)}\right]^{2}\right] \\
a_{1}=\frac{T_{\text {lim }}}{T_{\text {ref }}} \\
a_{2}=1-\left(\frac{1}{a_{1}}\right)
\end{array}\right.
$$

where $\lambda_{\text {dry }}$ and $\lambda_{\text {wet }}$ are the thermal conductivities under dry and wet conditions for soil, which are $0.3 \mathrm{~W} /(\mathrm{m} \cdot \mathrm{K})$ and $1 \mathrm{~W} /(\mathrm{m} \cdot \mathrm{K})$, respectively; $T_{\text {lim }}$ is the cable limit temperature, $363 \mathrm{~K} ; T_{\text {ref }}$ is the reference temperature of surrounding soil, $293 \mathrm{~K}$; and $Q_{e}$ is the electromagnetic loss density, which is defined as follows [24]:

$$
\begin{aligned}
Q_{e} & =Q_{\mathrm{rh}}+Q_{\mathrm{ml}}=\frac{1}{2} \operatorname{Re} \cdot\left(\vec{J} \cdot \vec{E}^{*}\right)+\frac{1}{2} \mathrm{Re} \cdot\left(j \omega \vec{B} \cdot \vec{H}^{*}\right), \\
\nabla \times \vec{A} & =\vec{B} \\
\vec{E} & =-j \omega \vec{A} \\
\vec{B} & =\mu \vec{H} \\
\vec{J} & =\sigma(T) \cdot \vec{E} .
\end{aligned}
$$

where $Q_{\mathrm{rh}}$ and $Q_{\mathrm{ml}}$ are the electrical loss density and magnetic loss density, respectively; Re is the real part of imaginary number; $\vec{J}$ is current density; $j$ is the imaginary unit; $\omega$ is the phase angle, $2 \pi f ; f$ is frequency of electrical excitation, $50 \mathrm{~Hz} ; \vec{B}$ is the magnetic induction intensity; $\vec{A}$ is the magnetic vector potential; $\vec{E}$ is the electric field intensity; $\vec{H}$ is magnetic field intensity; $\vec{E}^{*}$ and $\vec{H}^{*}$ are the 


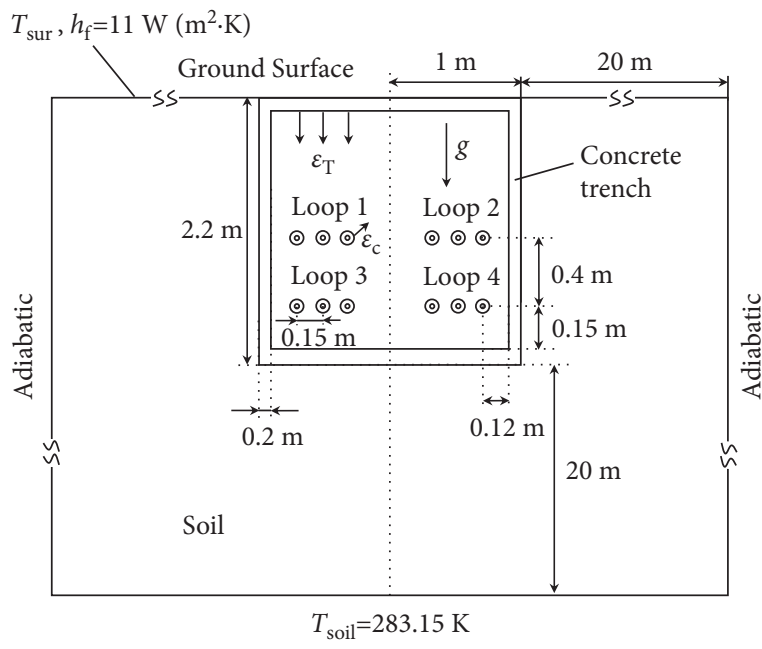

(a)

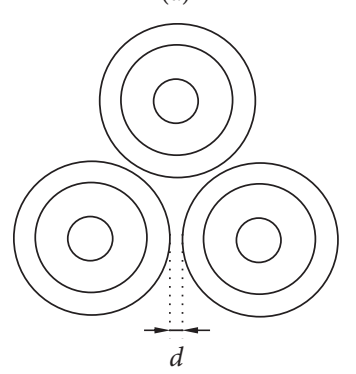

(c)

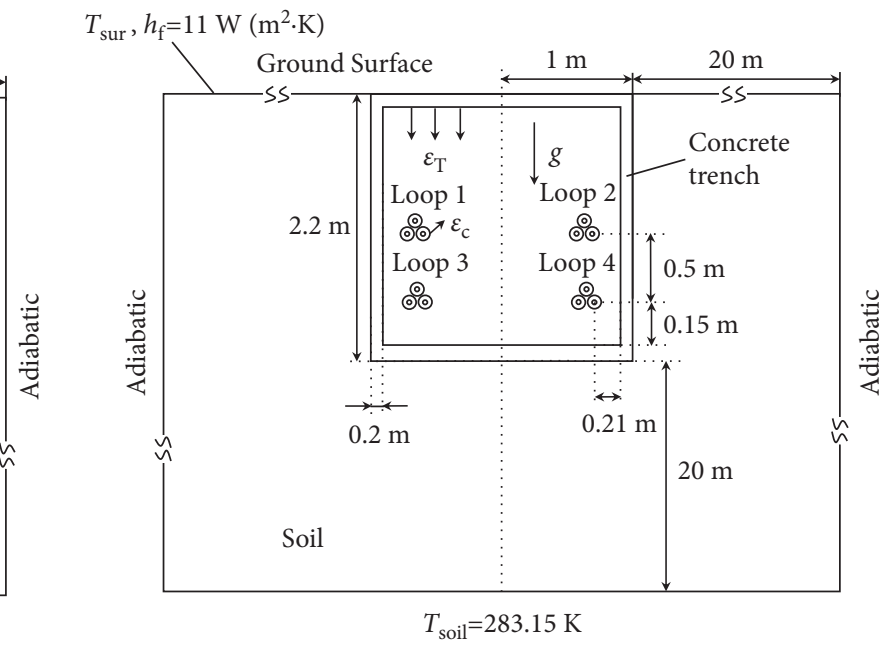

(b)

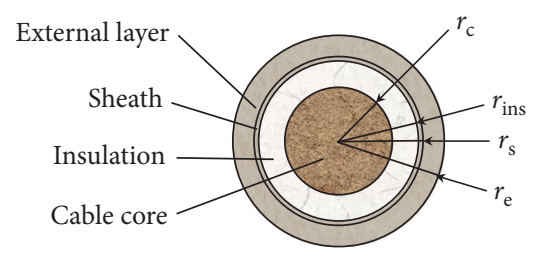

(d)

FIGURe 1: Physical model and geometrical structure for trench laying cable [22]: (a) flat-type trench laying cable; (b) trefoil-type trench laying cable; (c) trefoil cable arrangement; (d) cable structure.

TABLE 1: Typical geometric parameters for trench laying cable [22].

\begin{tabular}{lccc}
\hline$r_{c}(\mathrm{~mm})$ & $r_{\mathrm{ins}}(\mathrm{mm})$ & $r_{s}(\mathrm{~mm})$ & $r_{e}(\mathrm{~mm})$ \\
\hline 11.9 & 17.8 & 18.8 & 23.4 \\
\hline
\end{tabular}

conjugate complex numbers of $\vec{E}$ and $\vec{H}$; and $\sigma(T)$ is the electrical conductivity, which is defined as follows:

$$
\sigma(T)=\frac{1}{\rho_{\text {ref }}\left(1+\alpha\left(T-T_{\text {ref }}\right)\right)}
$$

where $\rho_{\text {ref }}$ is the reference electrical resistivity and $\alpha$ is the temperature coefficient.

The air flow in trench is a two-dimensional natural convection turbulent heat transfer, and governing equations are formulated as follows:

$$
\begin{aligned}
\nabla \cdot \vec{v} & =0 \\
\rho(\vec{v} \cdot \nabla \vec{v}) & =-\nabla p+\nabla \cdot\left[\left(\mu_{f}+\mu_{t}\right) \cdot\left(\nabla \vec{v}+(\nabla \vec{v})^{T}\right)\right]+\rho_{0} g\left[1-\beta\left(T-T_{0}\right)\right], \\
\rho(\vec{v} \cdot \nabla T) & =\nabla \cdot\left[\left(\frac{\lambda_{f}}{c_{p}}+\frac{\mu_{t}}{\sigma_{t}}\right) \cdot(\nabla T)\right],
\end{aligned}
$$

where $\vec{v}$ is the velocity vector; $T_{0}$ is the air reference temperature; $\rho$ and $\rho_{0}$ are the air density at $T$ and $T_{0}$, respectively; $p, g$, and $\beta$ are the pressure, gravitational acceleration, and volumetric expansion coefficient, respectively; $\mu_{f}$ and $\mu_{t}$ are the air dynamic viscosity and turbulence viscosity, respectively. $\lambda_{f}$ is the thermal conductivity of air; $c_{p}$ is the 
TABLE 2: Typical physical parameters for trench laying cable [22].

\begin{tabular}{lcccc}
\hline & Material & Thermal conductivity $(\mathrm{W} /(\mathrm{m} \cdot \mathrm{K}))$ & Electronic conductivity $(\mathrm{S} / \mathrm{m})$ & Relative dielectric constant \\
\hline Cable core & Copper & 377 & $5.998 \times 10^{7}$ & 1.0 \\
Insulation layer & XLPE & 0.285 & $1 \times 10^{-15}$ & 2.5 \\
Sheath layer & Aluminium & 238 & $3.774 \times 10^{7}$ & 1.0 \\
External layer & Polyethylene & 0.132 & $1 \times 10^{-15}$ & 2.5 \\
Concrete trench & Concrete & 1.73 & $1 \times 10^{-15}$ & 1.0 \\
Soil layer & Soil & 1 & $1 \times 10^{-15}$ & 1.0 \\
\hline
\end{tabular}

specific heat at the constant pressure of air; and $\sigma_{t}$ is the turbulence Prandtl number in energy equation.

As for air turbulent flow, the standard $k-\varepsilon$ model is adopted, which are defined as follows:

$$
\left\{\begin{array}{l}
\rho(\vec{v} \cdot \nabla k)=\nabla\left[\mu_{f}+\frac{\mu_{t}}{\sigma_{k}} \cdot \nabla k\right]+P_{k}-\rho \varepsilon, \\
\rho(\vec{v} \cdot \nabla \varepsilon)=\nabla\left[\left(\mu_{f}+\frac{\mu_{t}}{\sigma_{\varepsilon}}\right)\right]+C_{\varepsilon 1} \frac{\varepsilon}{k} P_{k}-C_{\varepsilon 2} \rho \frac{\varepsilon^{2}}{k},
\end{array}\right.
$$

where $k$ is the turbulent kinetic energy; $\varepsilon$ is the turbulent dissipation rate; $P_{k}$ is the shear production of turbulence; $\sigma_{k}$ and $\sigma_{\varepsilon}$ are the turbulence Prandtl numbers in $k$ and $\varepsilon$ equations; and $C_{\varepsilon 1}$ and $C_{\varepsilon 2}$ are the turbulent model parameters in $k$ and $\varepsilon$ equations.

The boundary conditions are set as follows:

$$
\begin{cases}\text { bottom soil Boundary: } & T=T_{\text {soil }}=283.15 \mathrm{~K}, \\ \text { Left and right soil boundary: } & \frac{\partial T}{\partial n}=0, \\ \text { Ground surface: } & \lambda \frac{\partial T}{\partial n}=h_{f}\left(T-T_{\text {sur }}\right), \\ \text { Air contact surface inside trench: } & \lambda_{i} \frac{\partial T}{\partial n}=h_{i}\left(T-T_{f}\right)+\frac{\sigma T^{4}-J_{i}}{\left(1-\varepsilon_{i}\right) / \varepsilon_{i}} ; \quad u=v=0\end{cases}
$$

where $T_{\text {soil }}$ is the deep soil temperature; $h_{f}$ is the equivalent heat transfer coefficient on the ground surface, which is set as $11 \mathrm{~W} /\left(\mathrm{m}^{2} \cdot \mathrm{K}\right) ; T_{\text {sur }}$ is the air temperature on the ground; $\lambda_{i}$ $(i=1,2)$ represents the thermal conductivity of cable external layer or concrete layer, respectively; $h_{i}(i=1,2)$ represents the convective heat transfer coefficient on the cable surface or trench inner surface; $T_{f}$ is the air temperature in the trench; $\varepsilon_{i}\left(\varepsilon_{c}\right.$ and $\left.\varepsilon_{\mathrm{T}}\right)$ represents the radiant emissivity on the cable surface or trench inner surface, respectively; $J_{i}\left(J_{c}\right.$ and $\left.J_{\mathrm{T}}\right)$ represents the effective radiation on the cable surface or trench inner surface, respectively; and $\sigma$ is the blackbody radiation constant.

In this study, the governing equations are solved with the Pardiso solver embedded in commercial code COMSOL Multiphysics 5.2 . The current frequency is set as $50 \mathrm{~Hz}$. The conservative interface flux conditions for mass, momentum, and heat transfer are adopted at the solid-solid and solidfluid interfaces. For convergence criteria, all residuals of the calculations are less than $10^{-3}$.

\section{Grid Independence Test and Model Validations}

3.1. Grid Independence Test. First, the grid independence tests were performed for both flat-type trench laying cable model (Figure 1(a)) and trefoil-type trench laying cable model (Figure 1(b)). For the test cases, the air temperature on the ground $\left(T_{\text {sur }}\right)$ is set as $293.15 \mathrm{~K}$, and the cable current for different loops are kept the same $(I=800 \mathrm{~A}, f=50 \mathrm{~Hz})$. The computational grids for different trench laying cable models are presented in Figure 2. The unstructured mesh is constructed for the computations, and the mesh is intensified near the surfaces of cable and trench wall. The cable maximum temperature $\left(T_{\max }\right)$ and electromagnetic loss $\left(\Phi_{\text {loss }}\right)$ with different computational grids are presented in Table 3. It shows that for the flat-type trench laying cable model, when the total element number changes from 27,610 (Grid 3) to 50,188 (Grid 4), the difference of cable maximum temperature $\left(T_{\max }\right)$ is $0.05 \%$, and the difference of 


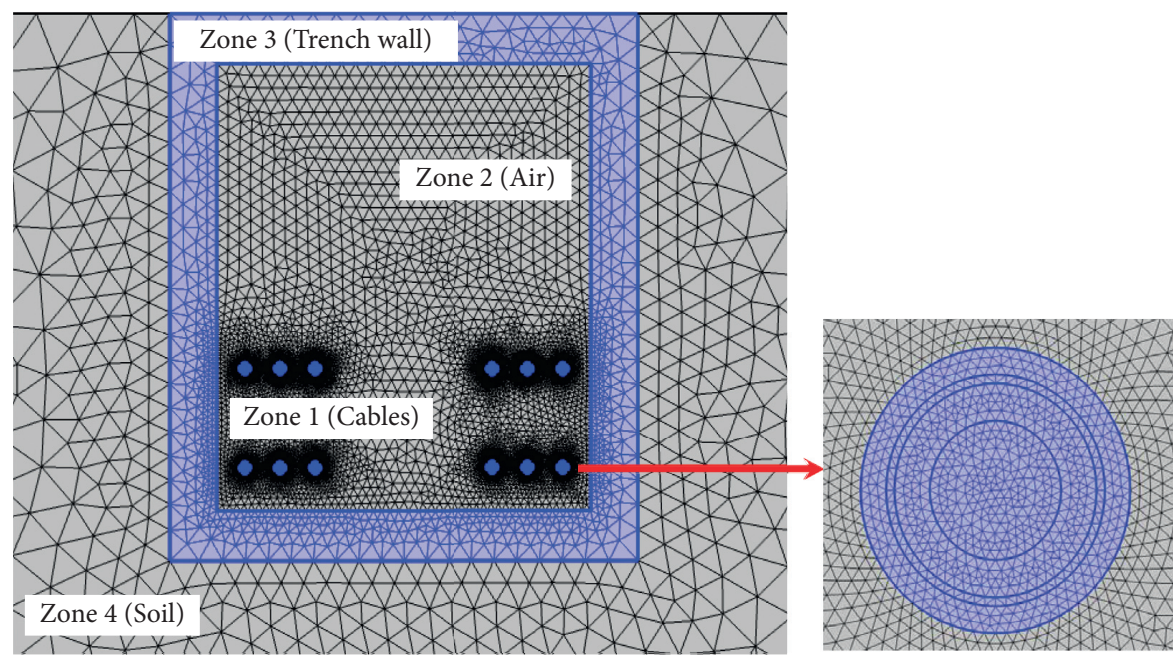

(a)

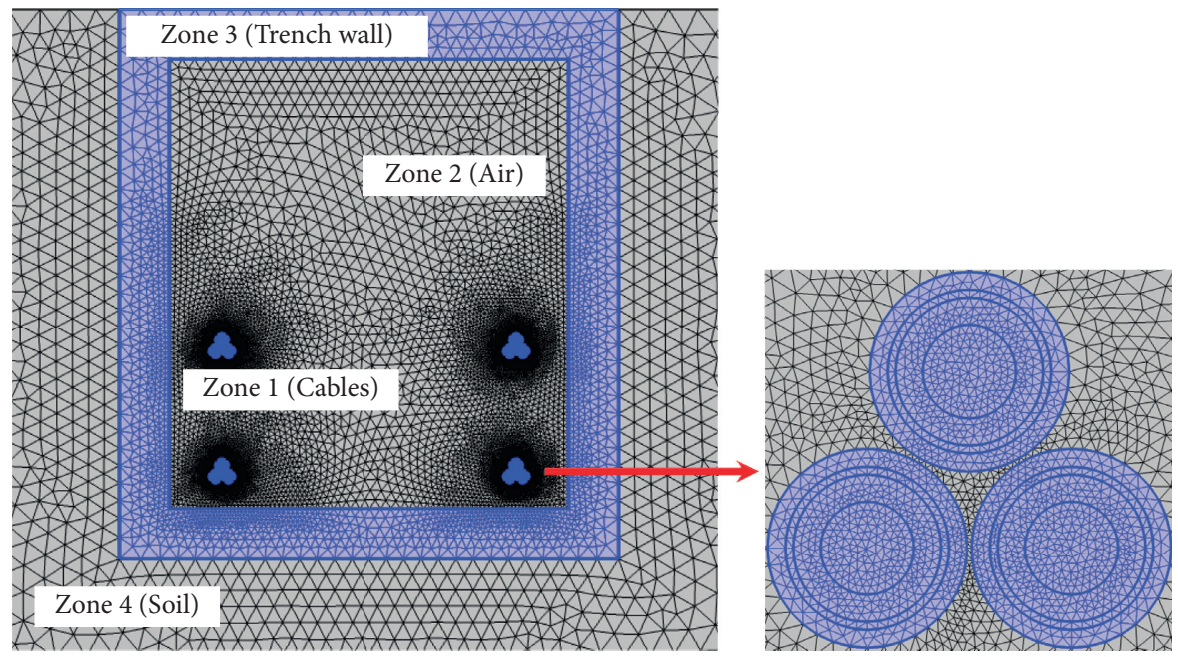

(b)

Figure 2: Computational grids for different trench laying cable models: (a) flat-type trench laying cable and (b) trefoil-type trench laying cable.

TABLE 3: Cable maximum temperature and electromagnetic loss with different computational grids $\left(T_{\text {sur }}=293.15 \mathrm{~K}, I=800 \mathrm{~A}\right.$, and $f=50 \mathrm{~Hz})$.

\begin{tabular}{|c|c|c|c|c|c|c|c|}
\hline Cable model & Grid & Region & Maximum grid size $(\mathrm{m})$ & $\begin{array}{l}\text { Minimum grid } \\
\text { size }(\mathrm{m})\end{array}$ & Total element number & $T_{\max }(\mathrm{K})$ & $\Phi_{\text {loss }}(\mathrm{W})$ \\
\hline \multirow{16}{*}{ Flat-type trench laying cable } & \multirow{4}{*}{ Grid 1} & Zone 1 & 0.0097 & 0.0024 & \multirow{4}{*}{10,881} & \multirow{4}{*}{336.520} & \multirow{4}{*}{190.65} \\
\hline & & Zone 2 & 0.2971 & 0.0049 & & & \\
\hline & & Zone 3 & 0.3192 & 0.0199 & & & \\
\hline & & Zone 4 & 3.1044 & 0.2489 & & & \\
\hline & \multirow{5}{*}{ Grid 2} & Zone 1 & 0.0057 & 0.0017 & \multirow{4}{*}{18,070} & \multirow{4}{*}{333.742} & \multirow{4}{*}{183.38} \\
\hline & & Zone 2 & 0.1137 & 0.0049 & & & \\
\hline & & Zone 3 & 0.1815 & 0.0181 & & & \\
\hline & & Zone 4 & 2.1844 & 0.1411 & & & \\
\hline & & Zone 1 & 0.0043 & 0.0015 & \multirow{4}{*}{27,610} & \multirow{4}{*}{333.708} & \multirow{4}{*}{182.55} \\
\hline & \multirow{3}{*}{ Grid 3} & Zone 2 & 0.0938 & 0.0042 & & & \\
\hline & & Zone 3 & 0.1515 & 0.0117 & & & \\
\hline & & Zone 4 & 1.8306 & 0.1117 & & & \\
\hline & \multirow{4}{*}{ Grid 4} & Zone 1 & 0.0024 & 0.0013 & \multirow{4}{*}{50,188} & \multirow{4}{*}{333.541} & \multirow{4}{*}{182.25} \\
\hline & & Zone 2 & 0.0682 & 0.0020 & & & \\
\hline & & Zone 3 & 0.1256 & 0.0117 & & & \\
\hline & & Zone 4 & 0.9978 & 0.0951 & & & \\
\hline
\end{tabular}


TABLE 3: Continued.

\begin{tabular}{|c|c|c|c|c|c|c|c|}
\hline Cable model & Grid & Region & Maximum grid size $(\mathrm{m})$ & $\begin{array}{l}\text { Minimum grid } \\
\text { size }(\mathrm{m})\end{array}$ & Total element number & $T_{\max }(\mathrm{K})$ & $\Phi_{\text {loss }}(\mathrm{W})$ \\
\hline \multirow{16}{*}{ Trefoil-type trench laying cable } & \multirow{4}{*}{ Grid 1} & Zone 1 & 0.0060 & 0.0015 & \multirow{4}{*}{14,408} & \multirow{4}{*}{342.287} & \multirow{4}{*}{190.67} \\
\hline & & Zone 2 & 0.1140 & 0.0013 & & & \\
\hline & & Zone 3 & 0.1815 & 0.0260 & & & \\
\hline & & Zone 4 & 2.5112 & 0.1411 & & & \\
\hline & \multirow{5}{*}{ Grid 2} & Zone 1 & 0.0059 & 0.0015 & \multirow{4}{*}{22,618} & \multirow{5}{*}{343.014} & \multirow{4}{*}{189.69} \\
\hline & & Zone 2 & 0.0911 & 0.0012 & & & \\
\hline & & Zone 3 & 0.1457 & 0.0227 & & & \\
\hline & & Zone 4 & 1.7810 & 0.1088 & & & \\
\hline & & Zone 1 & 0.0047 & 0.0011 & \multirow{4}{*}{27,798} & & \multirow{4}{*}{188.69} \\
\hline & \multirow{3}{*}{ Grid 3} & Zone 2 & 0.0885 & 0.0012 & & \multirow{3}{*}{341.779} & \\
\hline & & Zone 3 & 0.1173 & 0.0127 & & & \\
\hline & & Zone 4 & 0.9868 & 0.1031 & & & \\
\hline & \multirow{4}{*}{ Grid 4} & Zone 1 & 0.0033 & 0.0011 & \multirow{4}{*}{53,290} & \multirow{4}{*}{341.411} & \multirow{4}{*}{188.71} \\
\hline & & Zone 2 & 0.0877 & 0.0011 & & & \\
\hline & & Zone 3 & 0.1093 & 0.0103 & & & \\
\hline & & Zone 4 & 0.4872 & 0.0748 & & & \\
\hline
\end{tabular}

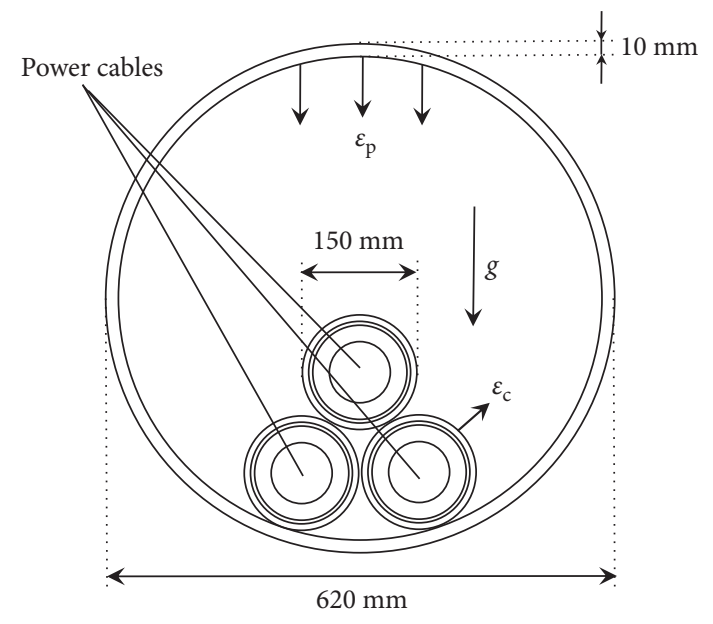

(a)

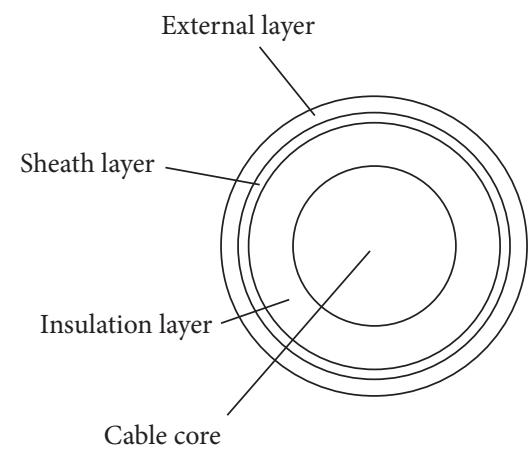

(b)

Figure 3: Physical model for pipe laying cable and cable structure [3]: (a) physical model for pipe laying cable and (b) cable structure.

electromagnetic loss $\left(\Phi_{\text {loss }}\right)$ is $0.16 \%$. Therefore, for the flattype trench laying cable model, the Grid 3 with total element number of 27,610 should be good enough for the test. For this grid, the minimum size of the grid element in the cable zone (Zone 1), air zone (Zone 2), trench wall zone (Zone 3), and soil zone (Zone 4 ) are $1.5 \mathrm{~mm}, 4.2 \mathrm{~mm}, 11.7 \mathrm{~mm}$, and $111.7 \mathrm{~mm}$, respectively. As for the trefoil-type trench laying cable model, when the total element number changes from 27,798 (Grid 3) to 53,290 (Grid 4), the difference of cable maximum temperature $\left(T_{\max }\right)$ is $0.11 \%$, and the difference of electromagnetic loss $\left(\Phi_{\text {loss }}\right)$ is $0.01 \%$. Therefore, for the trefoil-type trench laying cable model, the Grid 3 with total element number of 27,798 should be good enough for the test. For this grid, the minimum size of the grid element in the cable zone (Zone 1), air zone (Zone 2), trench wall zone (Zone 3), and soil zone (Zone 4) are $1.1 \mathrm{~mm}, 1.2 \mathrm{~mm}$, $12.7 \mathrm{~mm}$, and $103.1 \mathrm{~mm}$, respectively. Based on the aforementioned analysis, similar mesh settings to the Grid 3 $(27,610)$ for flat-type trench laying cable model and Grid 3
$(27,798)$ for trefoil-type trench laying cable model were finally adopted for the following simulations.

3.2. Model Validations. Subsequently, the computational model and methods are validated. Since numerical study on multiphysics coupling simulation for the trench laying cable is few, the numerical simulations for three-phase pipe laying cable [3] are restudied. The physical model for pipe laying cable [3] is presented in Figure 3. Three-phase cables are laid in a polyvinyl chloride (PVC) pipe. Both natural convection and radiation heat transfer are considered on the cable surfaces and pipe inner surface. The cable diameter is $150 \mathrm{~mm}$, the outer diameter of PVC pipe is $620 \mathrm{~mm}$ and its thickness is $10 \mathrm{~mm}$. The radiant emissivity on the cable surface is 0.8 , and it is 0.5 on the inner surface of PVC pipe. The equivalent heat transfer coefficient on the outer surface of PVC pipe $\left(h_{r}\right)$ is $5 \mathrm{~W} /\left(\mathrm{m}^{2} \cdot \mathrm{K}\right)$, and the environment temperature on the outside surface of PVC pipe $\left(T_{r}\right)$ is $293.15 \mathrm{~K}$. Typical geometrical and 
TABle 4: Typical geometrical and physical parameters for the pipe laying cable [3].

\begin{tabular}{lcccc}
\hline & Diameter $(\mathrm{mm})$ & Thermal conductivity $(\mathrm{W} /(\mathrm{m} \bullet \mathrm{K}))$ & Electronic conductivity $($ S/m) & Relative dielectric constant \\
\hline Cable core & 60.4 & 400 & $5.998 \times 10^{7}$ & 1.0 \\
Insulation layer & 120 & 0.286 & $1 \times 10^{-15}$ & 2.5 \\
Sheath layer & 140 & 238 & $3.774 \times 10^{7}$ & 1.0 \\
External layer & 150 & 0.280 & $1 \times 10^{-15}$ & 2.5 \\
PVC pipe & 620 & 0.167 & $1 \times 10^{-16}$ & 1.0 \\
\hline
\end{tabular}

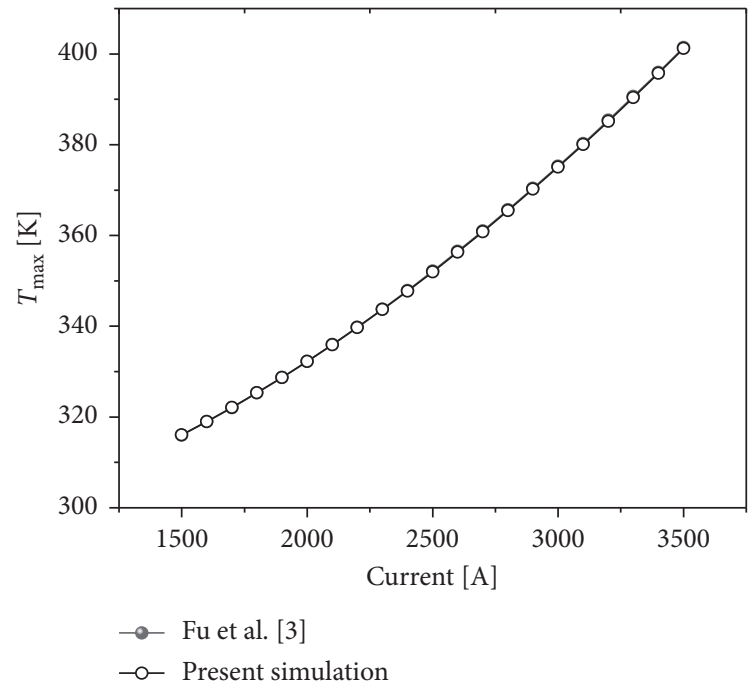

(a)

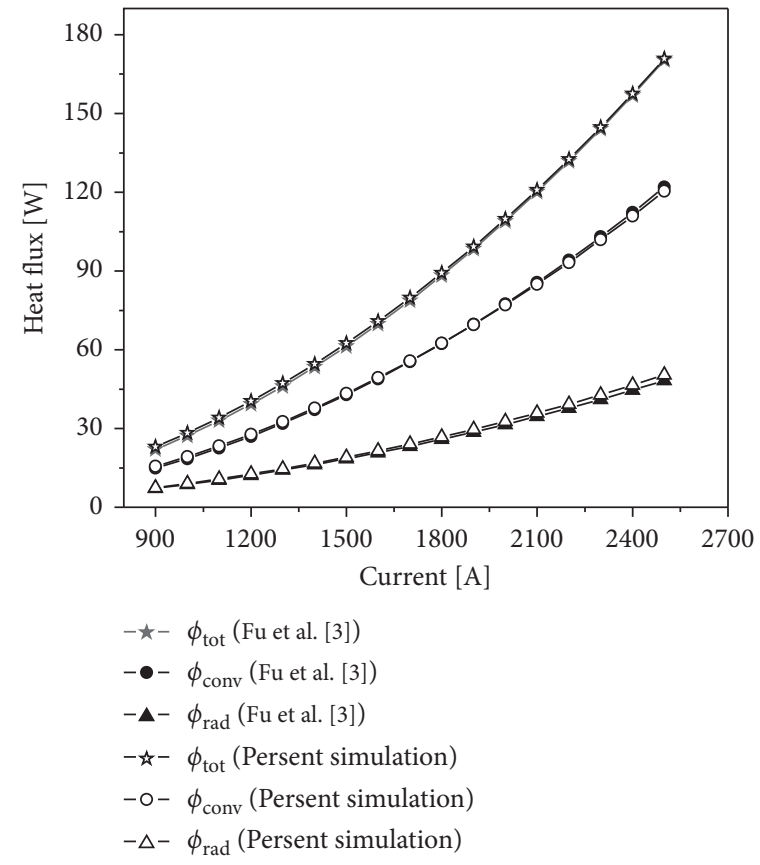

(b)

Figure 4: Computational results for pipe laying cable: (a) cable maximum temperature and (b) heat flux on cable surface.

physical parameters for the pipe laying cable [3] are listed in Table 4. The computational results for the cable maximum temperature $\left(T_{\max }\right)$, radiation heat flux $\left(\Phi_{\text {rad }}\right)$, convection heat flux $\left(\Phi_{\text {conv }}\right)$, and total heat flux $\left(\Phi_{\text {tot }}\right)$ on the cable surface are presented in Figure 4. It shows that the present computational results are in good agreement with those as reported by $\mathrm{Fu}$ et al. [3], where the maximum deviations for $T_{\text {max }}, \Phi_{\text {rad }}, \Phi_{\text {conv }}$, and $\Phi_{\text {tot }}$ are $0.056 \%, 4.70 \%, 4.41 \%$, and $4.47 \%$, respectively.

In addition, since the air flow inside PVC pipe is laminar flow in Fu et al.'s study [3], the turbulence natural convection heat transfer in a two-dimensional square cavity [25] is restudied. The physical model for the two-dimensional square cavity [25] is presented in Figure 5. It shows that the top and bottom walls of the cavity are adiabatic. Two vertical walls are high temperature and low temperature walls, where the wall temperature is kept constant and the temperature difference is $40 \mathrm{~K}$. The computational results for the average Nusselt number $\left(\mathrm{Nu}_{\text {ave }}\right)$ are presented in Table 5. It shows that the average Nusselt numbers $\left(\mathrm{Nu}_{\text {ave }}\right)$ obtained from the present simulations can agree well with those in Kuznetsov and Sheremet's study [25], and the maximum deviation is $6.26 \%$.

\section{Prediction Algorithm}

In this study, an adaptive optimized particle swarm optimization algorithm (LFVPSO) is proposed based on Levy flight algorithm, and it is used to modify the back propagation neural network algorithm (LFVPSO-BPNN). Then combined with numerical simulations, a network algorithm for temperature prediction of trench laying cable is developed using LFVPSO-BPNN. Finally, the maximum current capacity of four-loop three-phase trench laying cable is calculated using LFVPSO-BPNN together with genetic algorithm (GA\&LFVPSO-BPNN).

4.1. LFVPSO-BPNN Algorithm. Back propagation neural network algorithm (BPNN) is a multilayer feed-forward network algorithm trained by back propagation of computational errors [26], and it is often used to predict and analyze nonlinear correlations. As presented in Figure 6, the BPNN topology structure is composed of input layer, hidden layers, and output layer [27].

Where $x$ is the input variable of BPNN; $W^{h}$ represents the transitive relation between input layer and hidden layer; $\theta^{h}$ is 


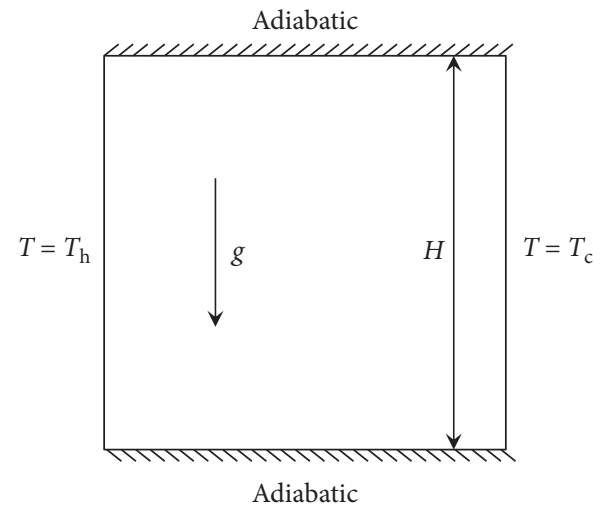

FIGURe 5: Physical model for two-dimensional square cavity [25].

TABle 5: Computational results for $\mathrm{Nu}_{\mathrm{ave}}$ of present simulation and the study by Kuznetsov and Sheremet [25].

\begin{tabular}{lccc}
\hline $\mathrm{Ra}$ & $\mathrm{Nu}_{\text {ave }}$ (present simulation) & Kuznetsov and Sheremet's study [25] & Deviation (\%) \\
\hline $10^{7}$ & 18.60 & 17.72 & 4.97 \\
$10^{8}$ & 35.50 & 33.41 & 6.26 \\
\hline
\end{tabular}

the threshold of the hidden layer neuron; $W^{o}$ represents the transitive relation between hidden layer and output layer; $\theta^{\circ}$ is the threshold of output layer neuron; and $y$ is the output variable of BPNN.

Before BPNN training, the weights and thresholds between neurons should be preset. Improper setting of weights and thresholds will lead to unreasonable prediction results. To improve the prediction accuracy of BPNN algorithm, the weights and thresholds of the network can be optimized in advance. Particle swarm optimization algorithm (PSO) has a good advantage in multiobjective optimizations. When large number of weights and thresholds of BPNN need to be optimized, the PSO algorithm can be used for the optimizations [28, 29]. However, it should be noted that the PSO algorithm may lead to local optimum results. Try to avoid this defect of PSO algorithm, the Levy flight algorithm is recommended to improve the performance of PSO [30, 31]. Levy flight trajectory is composed of frequent short-distance random walks and occasional long-distance random jumps. The Levy flight extremum can produce random jumps and extreme speed changes in direction, which is helpful to expand searching space. Therefore, combining PSO algorithm with Levy flight algorithm, the local optimum risk of PSO algorithm might be greatly reduced. Huseyin and Uğuz [30] combined PSO algorithm with Levy flight algorithm to update the position of particle swarm, and then selected the optimum particle position to calculate the optimum value of the objective function. This improved PSO algorithm (LFPSO) can effectively avoid the local optimum risk of PSO algorithm, but its computation time is relatively long because sometimes the position of particle swarm is needed to be calculated twice for a single iteration during the iterative process. Jensi and Jiji [31] proposed an enhanced PSO algorithm together with Levy flight algorithm by setting a random number (rand $\in[0,1])$ to combine the PSO algorithm with Levy flight algorithm (PSOLF). When rand $\in[0.5,1]$, the PSO algorithm and Levy flight algorithm were combined with linearly decreasing weight method to update the position of particle swarm and calculate the optimum value of the objective function. When rand $\in[0,0.5)$, only PSO algorithm was used to update the position of particle swarm and calculate the optimum value of the objective function. As compared with LFPSO algorithm [30], the computation time of this algorithm (PSOLF) can be greatly reduced. However, when the weight of the Levy flight algorithm becomes smaller, the local optimum risk of PSOLF algorithm would increase. Therefore, in this paper, based on the study of Jensi and Jiji [31], an adaptive optimized PSO algorithm (LFVPSO) is further proposed together with Levy flight algorithm, and it is used to find the optimum weights and thresholds of BPNN. For the LFVPSO algorithm, when rand $\epsilon[0.5,1]$, the PSO algorithm and Levy flight algorithm are directly combined, and the adaptive mutation idea of genetic algorithm (GA) is also adopted to update the position of particle swarm and calculate the optimum value of the objective function. As compared with PSOLF algorithm [31], the local optimum risk of present algorithm (LFVPSO) would be reduced, and its prediction accuracy would be improved. According to the authors' knowledge, almost no such studies were performed yet.

In LFVPSO algorithm, a random number (rand $\in[0,1]$ ) is set first. When rand $\in[0,0.5)$, the PSO algorithm is used to update the position of particle swarm. When rand $\in[0.5,1]$, the PSO algorithm is combined with Levy flight algorithm to update the position of particle swarm. Then, find out the position of the particle with the worst fitness in the current particle swarm and update particle swarm position to far away from the worst particle position at a certain rate. The next particle swarm position is calculated as in equation (8). Meanwhile, the adaptive mutation idea of genetic algorithm (GA) is also adopted, and the adaptive mutation operation is introduced into the PSO algorithm. For this operation, a random number ( rand $^{\prime} \in[0,1]$ ) is set, and the position of some particle in the swarm is randomly updated again with a certain probability as rand ${ }^{\prime}>0.95$. The flowchart for BPNN 


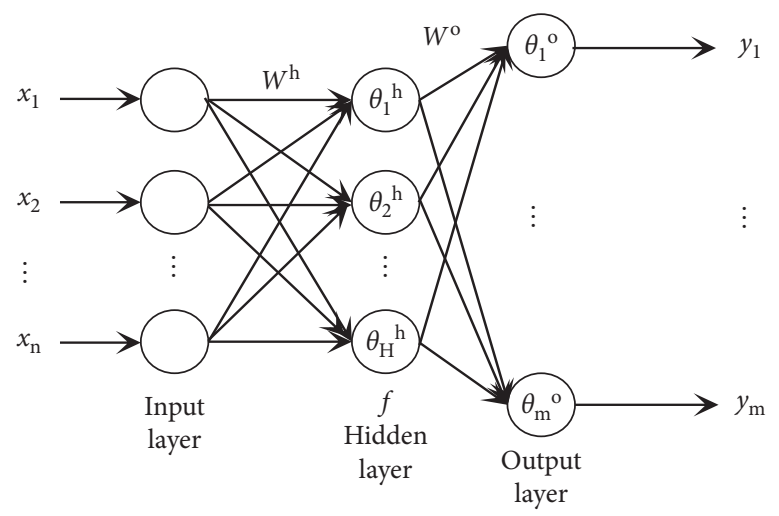

FiguRe 6: BPNN topology structure [27].

LFVPSO

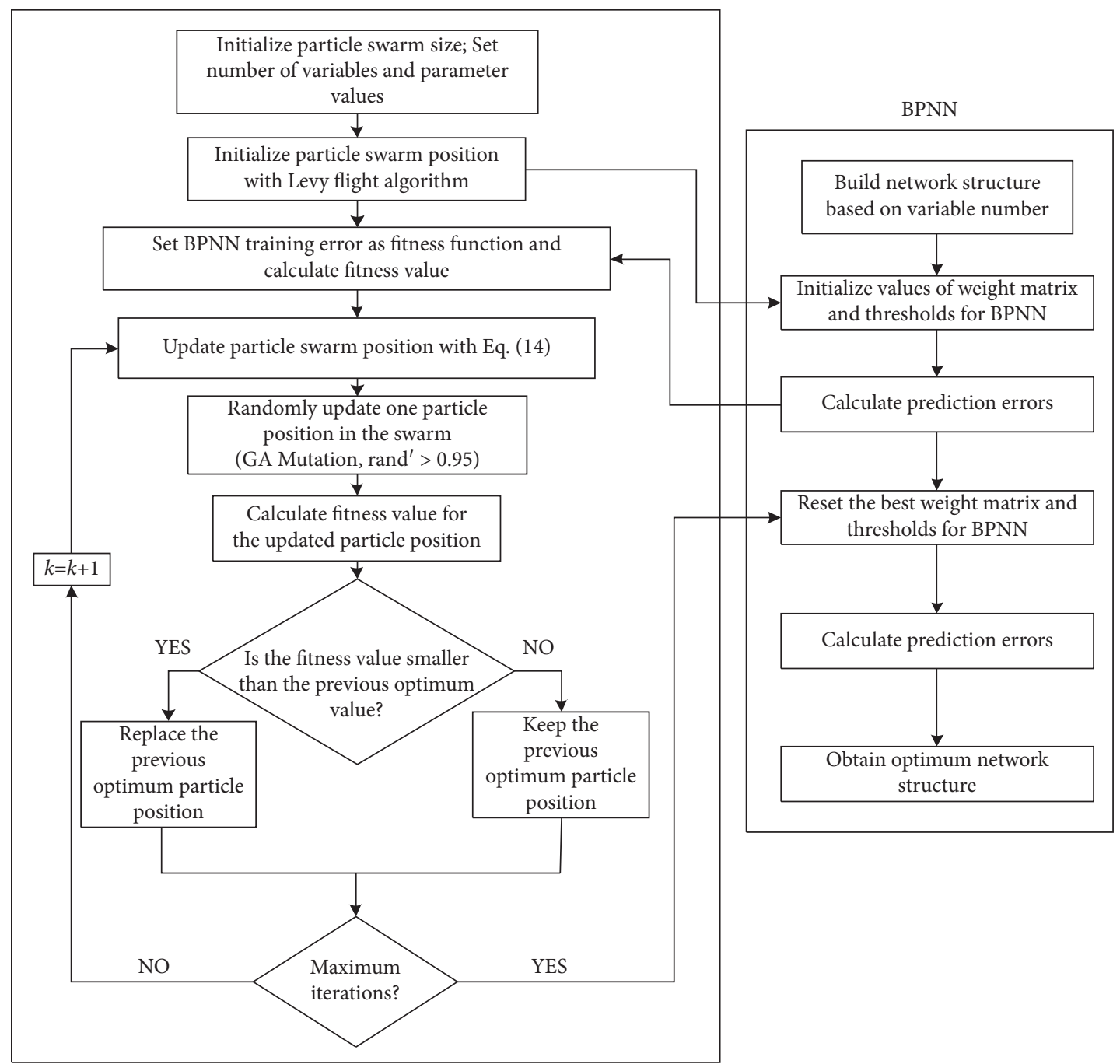

Figure 7: The flowchart for BPNN optimization with LFVPSO (LFVPSO-BPNN).

optimization with LFVPSO (LFVPSO-BPNN) is presented in Figure 7. In LFVPSO algorithm, the prediction error of BPNN is set as fitness function. The particle swarm position is randomly initialized using Levy flight algorithm and updated with equation (8). The optimum weights and thresholds of BPNN are calculated with iteration method to minimize the fitness function. Based on these operations, the optimum BPNN prediction model is constructed, which is 


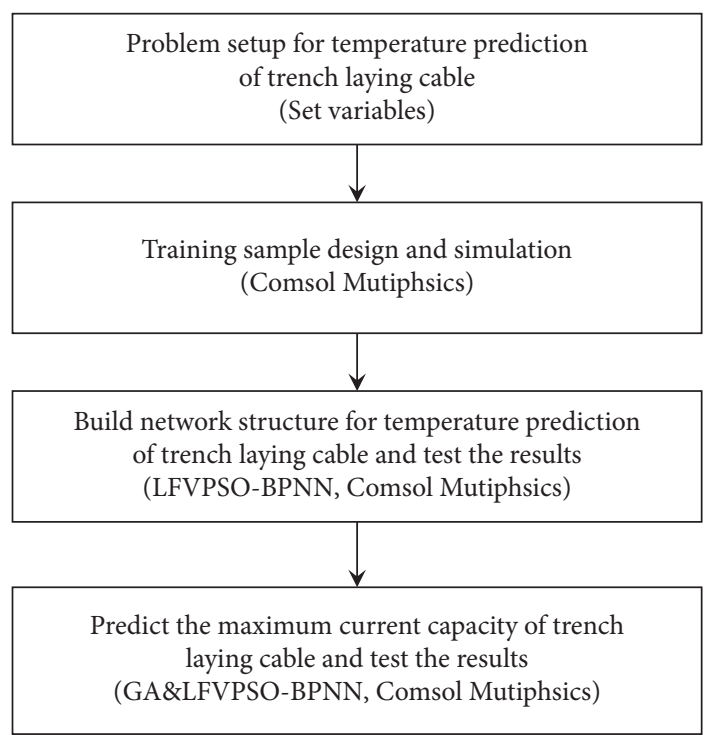

FIgURE 8: The flowchart of prediction algorithm for temperature rise of trench laying cable.

the LFVPSO-BPNN model. The particle swarm position is updated and calculated as follows:

$$
\left\{\begin{array}{lrl}
X_{i}^{k+1}=X_{i}^{k}+a_{1} V_{i}^{k+1}-a_{2} r_{1}\left(P_{w}^{k}-X_{i}^{k}\right), & & \text { rand } \in[0,0.5), \\
X_{i}^{k+1}=X_{i}^{k}+a_{1} V_{i}^{k+1}+\left[\vartheta_{0} \cdot\left(X_{i}^{k}-P_{g}^{k}\right)\right] \otimes \operatorname{Levy}(\beta)-a_{2} r_{3} \cdot\left(P_{w}^{k}-X_{i}^{k}\right), & & \text { rand } \in[0.5,1]
\end{array}\right.
$$

where $X_{i}^{k+1}$ is the position of particle $i$ at iteration $k+1 ; X_{i}^{k}$ is the position of particle $i$ at iteration $k ; V_{i}^{k+1}$ is the velocity of particle $i$ at iteration $k+1 ; P_{w}^{k}$ is the position of the particle with the worst fitness in the current particle swarm; $P_{g}^{k}$ is the position of the particle with the best fitness in the previous particle swarm; $a_{1}$ is the scaling factor of velocity weight, 0.2 ; $a_{2}$ and $\vartheta_{0}$ are the step scaling factors, $0.01 ; r_{1}$ is a random number between 0 and 1 ; and $\beta$ is the Levy distribution index.

4.2. Temperature Prediction Network of Trench Laying Cable. When the trench structure and cable layout are determined, the cable maximum temperature of each loop in the trench $\left(T_{\max , i}\right)$ is mainly affected by the air temperature on the ground ( $\left.T_{\text {sur }}\right)$ and cable current of each loop $\left(I_{i}\right)$, and the maximum current capacity of trench laying cable $\left(I_{t, \max }\right)$ is mainly affected by $T_{\text {sur }}$. Therefore, in this study, $T_{\text {sur }}$ and $I_{i}$ are selected as the input variables, $T_{\max , i}$ is selected as the output variable, and a temperature prediction network of trench laying cable is developed with LFVPSO-BPNN. Then, $I_{t, \max }$ was calculated using LFVPSO-BPNN together with genetic algorithm (GA), where $T_{\text {sur }}$ is set as the input variable, and the maximum value of $T_{\max , i}$ should not exceed the safe operating temperature of cable $(363.15 \mathrm{~K})$. The flowchart of prediction algorithm for temperature rise of trench laying cable is presented in Figure 8. First, for different trench laying cable models, including flattype laying model (Figure 1(a)) and trefoil-type laying model (Figure 1(b)), the input variables of training samples $\left(T_{\text {sur }}\right.$ and
$I_{i}$ ) for temperature prediction network of trench laying cable (LFVPSO-BPNN) are selected using random sampling function. With this method, 80 training samples are selected for each cable model. The input variables of typical training samples for LFVPSO-BPNN are listed in Table 6, where $T_{\text {sur }}$ changes from $283.15 \mathrm{~K}$ to $313.15 \mathrm{~K}$, and $I_{i}$ changes from $200 \mathrm{~A}$ to $1200 \mathrm{~A}$. Based on the input variables of training samples in Table 6, the heat transfer processes for trench laying cables are numerically simulated with COMSOL Multiphysics, and the computational results of $T_{\text {max }, i}$ are set as the output variables of LFVPSO-BPNN. Then, the temperature prediction network for trench laying cable (LFVPSO-BPNN) is trained and constructed, and the predicted results of $T_{\text {max }, i}$ with LFVPSOBPNN are further validated using COMSOL Multiphysics. Finally, the maximum current capacity of trench laying cable ( $\left.I_{t \text {,max }}\right)$ under different $T_{\text {sur }}$ is calculated using LFVPSO-BPNN together with genetic algorithm (GA\&LFVPSO-BPNN). During the iteration process, the $T_{\text {sur }}$ should be set in advance, and the maximum value of $T_{\max , i}$ should not exceed the safe operating temperature of cable $(363.15 \mathrm{~K})$. After that, the predicted results with GA\&LFVPSO-BPNN should also be validated using COMSOL Multiphysics.

In this study, there are 5 input variables and 4 output variables in the temperature prediction network for trench laying cable (LFVPSO-BPNN). The input variables are $T_{\text {sur }}$ and $I_{i}(i=1,2,3$, and 4$)$, and the output variables are $T_{\max , i}$ $(i=1,2,3$, and 4$)$. One hidden layer is set in the present temperature prediction network, and the hidden layer is 
TABLE 6: Input variables of typical training samples for LFVPSO-BPNN.

\begin{tabular}{|c|c|c|c|c|c|}
\hline Samples & $T_{\text {sur }}(\mathrm{K})$ & $I_{1}(\mathrm{~A})$ & $I_{2}(\mathrm{~A})$ & $I_{3}(\mathrm{~A})$ & $I_{4}(\mathrm{~A})$ \\
\hline \multicolumn{6}{|c|}{ Flat-type trench laying cable } \\
\hline 1 & 308.11 & 554.02 & 514.73 & 861.26 & 741.50 \\
\hline 2 & 295.38 & 207.81 & 625.83 & 423.51 & 956.98 \\
\hline 3 & 302.36 & 788.37 & 633.43 & 444.17 & 628.96 \\
\hline$\ldots$ & $\ldots$ & $\ldots$ & $\ldots$ & $\ldots$ & $\ldots$ \\
\hline 78 & 311.10 & 1014.92 & 340.50 & 1079.87 & 295.38 \\
\hline 79 & 312.90 & 356.64 & 993.89 & 841.81 & 539.38 \\
\hline 80 & 287.40 & 637.42 & 946.18 & 667.91 & 1060.83 \\
\hline \multicolumn{6}{|c|}{ Trefoil-type trench laying cable } \\
\hline 1 & 310.92 & 1099.94 & 724.11 & 320.20 & 377.79 \\
\hline 2 & 292.43 & 929.32 & 711.42 & 404.30 & 270.93 \\
\hline 3 & 293.66 & 285.55 & 267.38 & 1088.39 & 433.17 \\
\hline$\ldots$ & $\ldots$ & $\ldots$ & $\ldots$ & $\ldots$ & $\ldots$ \\
\hline 78 & 311.67 & 764.76 & 716.10 & 641.85 & 374.49 \\
\hline 79 & 288.16 & 869.65 & 976.86 & 877.1 & 604.80 \\
\hline 80 & 303.72 & 848.03 & 633.37 & 339.76 & 951.93 \\
\hline
\end{tabular}

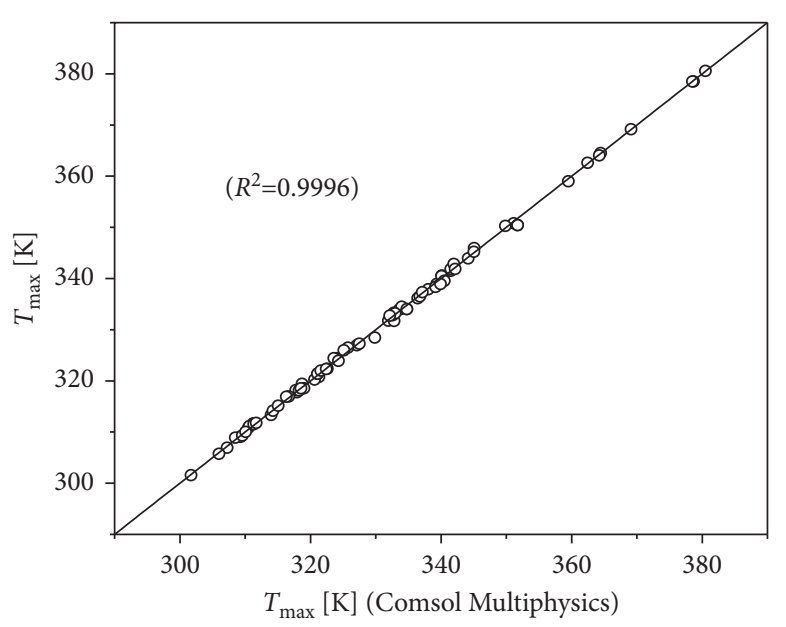

- LFVPSO-BPNN

(a)

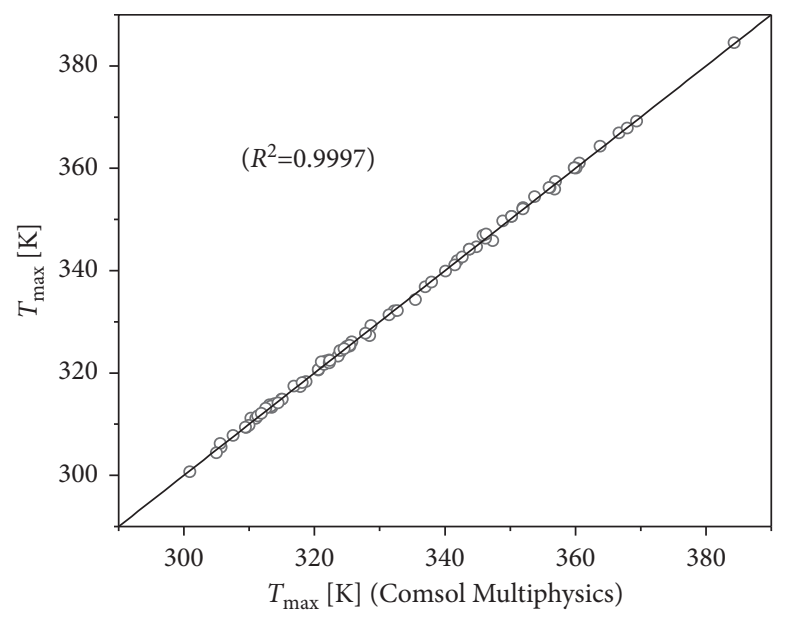

○ LFVPSO-BPNN

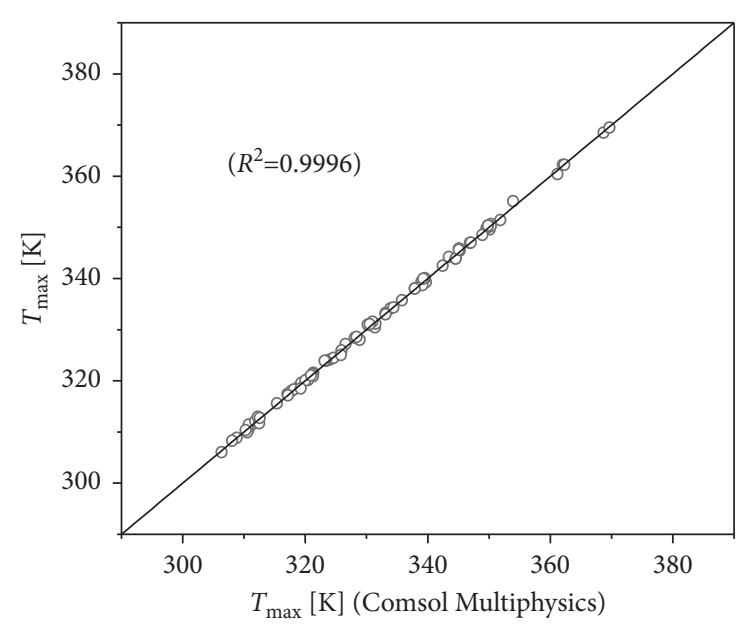

- LFVPSO-BPNN

(b)

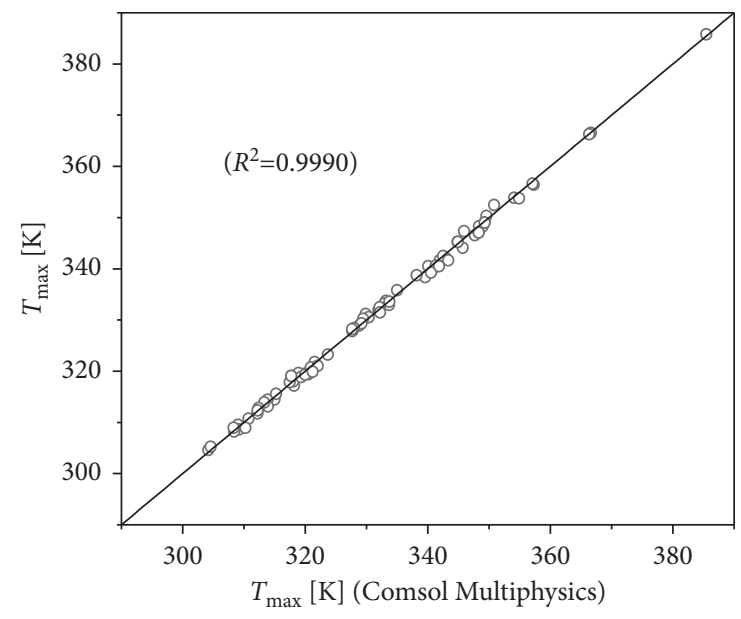

○ LFVPSO-BPNN

(c)

(d)

Figure 9: The prediction and simulation results of cable maximum temperature for different loops in the trench (80 training samples for the flat-type trench laying cable model): (a) Loop 1; (b) Loop 2; (c) Loop 3; (d) Loop 4. 


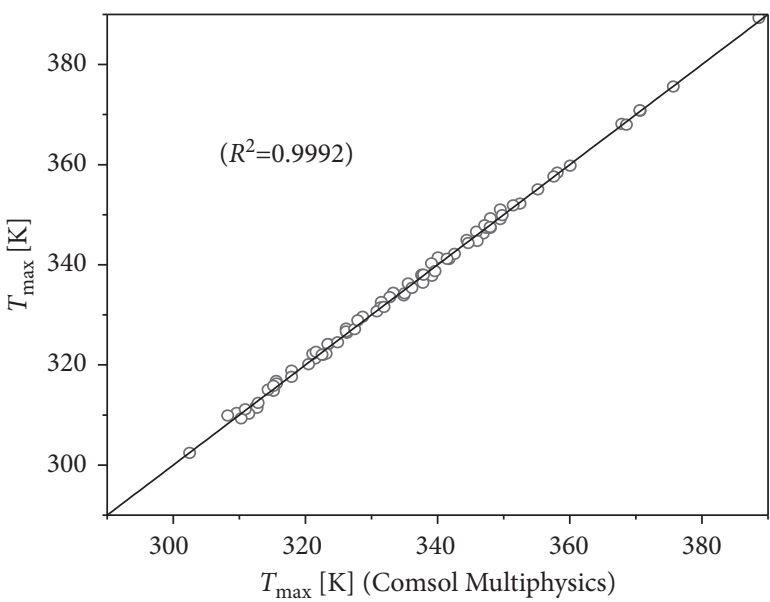

○ LFVPSO-BPNN

(a)

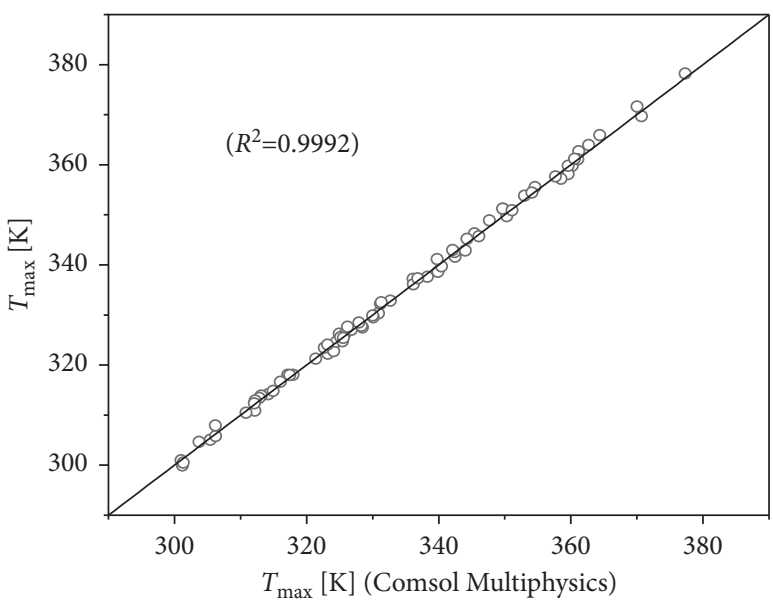

。 LFVPSO-BPNN

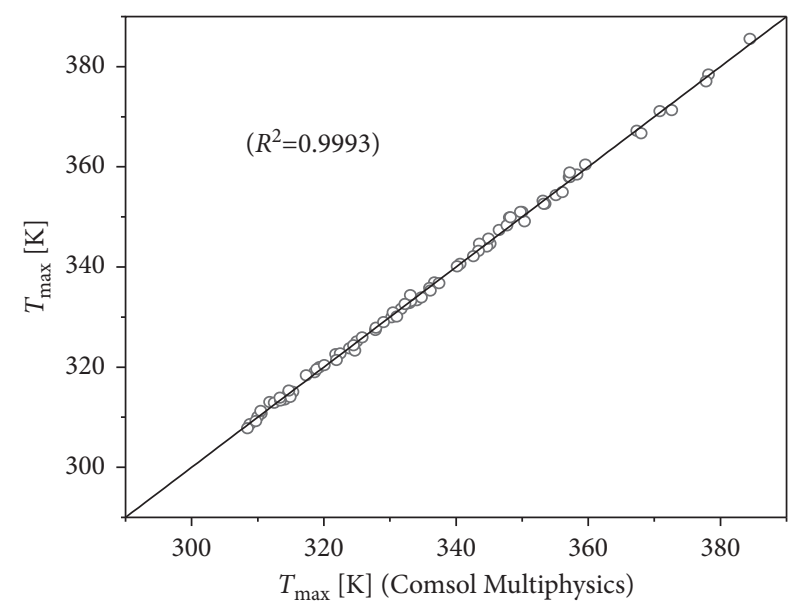

LFVPSO-BPNN

(b)

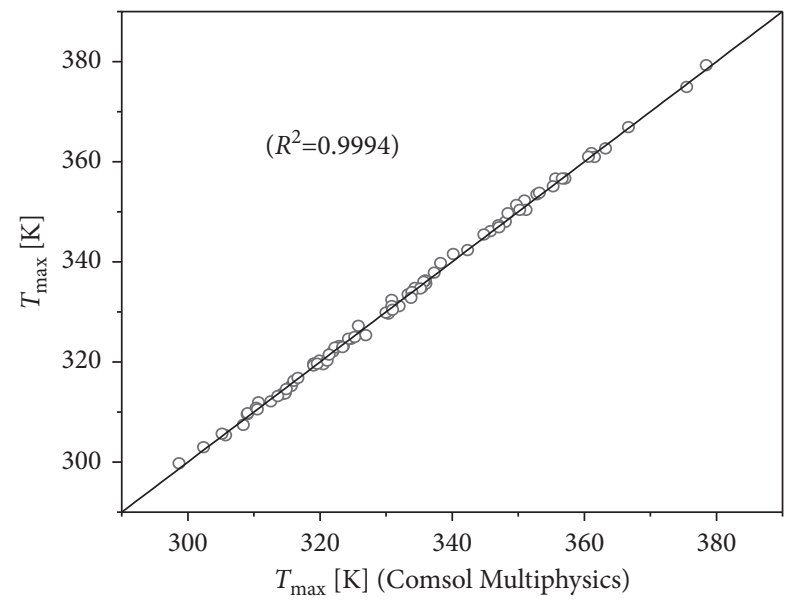

- LFVPSO-BPNN

(c)

(d)

FIGURE 10: The prediction and simulation results of cable maximum temperature for different loops in the trench (80 training samples for the trefoil-type trench laying cable model): (a) Loop 1; (b) Loop 2; (c) Loop 3; (d) Loop 4.

TABLE 7: The prediction and simulation results of cable maximum temperature for different loops in the trench (5 random test samples for the flat-type trench laying cable models).

\begin{tabular}{|c|c|c|c|c|c|c|c|c|c|}
\hline & Case & \multicolumn{2}{|c|}{$T_{\text {sur }}(\mathrm{K})$} & $I_{1}(\mathrm{~A})$ & \multicolumn{2}{|c|}{$I_{2}(\mathrm{~A})$} & \multicolumn{2}{|c|}{$I_{3}(\mathrm{~A})$} & $I_{4}(\mathrm{~A})$ \\
\hline & 1 & \multicolumn{2}{|c|}{304.33} & 941.11 & \multicolumn{2}{|c|}{825.35} & \multicolumn{2}{|c|}{485.39} & 1055.20 \\
\hline & 2 & \multicolumn{2}{|c|}{284.10} & 231.00 & \multicolumn{2}{|c|}{594.87} & \multicolumn{2}{|c|}{543.40} & 888.97 \\
\hline Input & 3 & \multicolumn{2}{|c|}{291.46} & 915.68 & \multicolumn{2}{|c|}{368.19} & \multicolumn{2}{|c|}{640.79} & 601.03 \\
\hline & 4 & \multicolumn{2}{|c|}{310.67} & 337.14 & \multicolumn{2}{|c|}{943.24} & \multicolumn{2}{|c|}{684.51} & 1096.52 \\
\hline & 5 & \multicolumn{2}{|c|}{305.59} & 275.99 & \multicolumn{2}{|c|}{559.80} & \multicolumn{2}{|c|}{433.88} & 920.06 \\
\hline & \multirow{2}{*}{ Case } & \multicolumn{4}{|c|}{ LFVPSO-BPNN } & \multicolumn{4}{|c|}{ COMSOL Multiphysics } \\
\hline & & $T_{\max , 1}(\mathrm{~K})$ & $T_{\max , 2}(\mathrm{~K})$ & $T_{\max , 3}(\mathrm{~K})$ & $T_{\max , 4}(\mathrm{~K})$ & $T_{\max , 1}(\mathrm{~K})$ & $T_{\max , 2}(\mathrm{~K})$ & $T_{\max , 3}(\mathrm{~K})$ & $T_{\max , 4}(\mathrm{~K})$ \\
\hline \multirow{5}{*}{ Output } & 1 & 355.53 & 348.99 & 336.81 & 364.49 & 354.91 & 348.70 & 336.03 & 363.27 \\
\hline & 2 & 297.51 & 307.24 & 304.27 & 322.88 & 298.35 & 307.83 & 305.95 & 322.32 \\
\hline & 3 & 331.44 & 309.58 & 319.49 & 315.85 & 331.42 & 309.83 & 319.21 & 317.43 \\
\hline & 4 & 337.21 & 360.46 & 346.99 & 371.73 & 336.68 & 360.09 & 347.39 & 371.04 \\
\hline & 5 & 318.92 & 326.98 & 322.51 & 344.59 & 319.33 & 326.85 & 322.64 & 343.92 \\
\hline
\end{tabular}

composed of 10 neuron nodes. Therefore, there are 104 weights and thresholds need to be optimized for the prediction network. The weight and threshold for the prediction network are set to be ranged in $[-5,5]$, and the number of particle swarm for LFVPSO is set to 60 . The fitness function of present prediction network is defined as follows: 
TABLE 8: The prediction and simulation results of cable maximum temperature for different loops in the trench (5 random test samples for the trefoil-type trench laying cable models).

\begin{tabular}{|c|c|c|c|c|c|c|c|c|c|}
\hline & Case & $T_{\text {sur }}(\mathrm{K})$ & \multicolumn{2}{|c|}{$I_{1}(\mathrm{~A})$} & \multicolumn{2}{|c|}{$I_{2}(\mathrm{~A})$} & \multicolumn{2}{|c|}{$I_{3}(\mathrm{~A})$} & $I_{4}(\mathrm{~A})$ \\
\hline & 1 & 293.54 & \multicolumn{2}{|c|}{596.05} & \multicolumn{2}{|c|}{765.13} & \multicolumn{2}{|c|}{394.86} & 828.06 \\
\hline & 2 & 305.35 & \multicolumn{2}{|c|}{866.33} & \multicolumn{2}{|c|}{643.07} & \multicolumn{2}{|c|}{633.3} & 375.24 \\
\hline Input & 3 & 306.64 & \multicolumn{2}{|c|}{552.56} & \multicolumn{2}{|c|}{793.42} & \multicolumn{2}{|c|}{785.18} & 867.68 \\
\hline & 4 & 305.80 & \multicolumn{2}{|c|}{885.1} & \multicolumn{2}{|c|}{521.95} & \multicolumn{2}{|c|}{454.42} & 686.91 \\
\hline & 5 & 309.71 & \multicolumn{2}{|c|}{456.11} & & & \multicolumn{2}{|c|}{646.8} & 1015.99 \\
\hline & \multirow[t]{2}{*}{ Case } & \multicolumn{4}{|c|}{ LFVPSO-BPNN } & \multicolumn{4}{|c|}{ COMSOL Multiphysics } \\
\hline & & $T_{\max , 1}(\mathrm{~K})$ & $T_{\max , 2}(\mathrm{~K})$ & $T_{\max , 3}(\mathrm{~K})$ & $T_{\max , 4}(\mathrm{~K})$ & $T_{\max , 1}(\mathrm{~K})$ & $T_{\max , 2}(\mathrm{~K})$ & $T_{\max , 3}(\mathrm{~K})$ & $T_{\max , 4}(\mathrm{~K})$ \\
\hline \multirow{5}{*}{ Output } & 1 & 323.46 & 331.00 & 314.61 & 336.96 & 322.27 & 331.47 & 313.84 & 337.53 \\
\hline & 2 & 347.95 & 336.14 & 336.14 & 324.74 & 348.10 & 335.48 & 335.70 & 325.09 \\
\hline & 3 & 337.69 & 350.01 & 349.72 & 357.11 & 338.18 & 350.24 & 350.07 & 357.03 \\
\hline & 4 & 349.50 & 330.27 & 328.46 & 338.26 & 350.35 & 329.16 & 328.80 & 337.64 \\
\hline & 5 & 342.75 & 378.23 & 350.32 & 375.5 & 343.07 & 377.40 & 350.45 & 376.17 \\
\hline
\end{tabular}

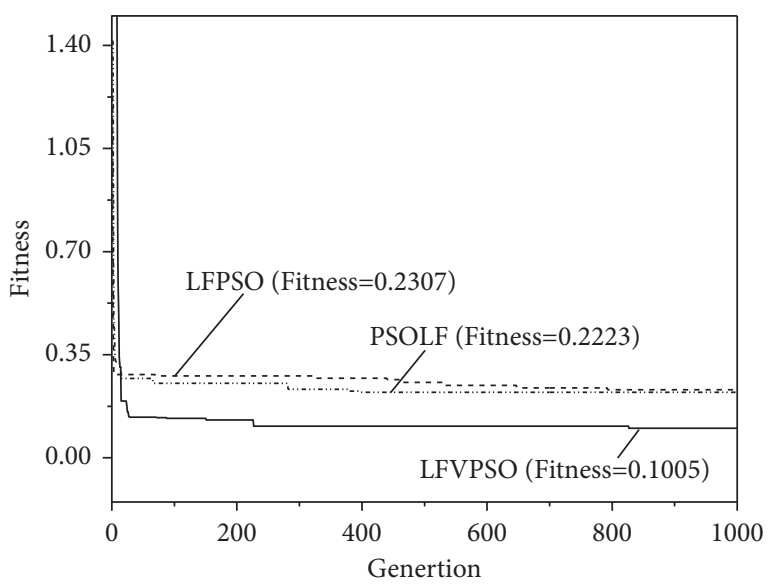

(a)

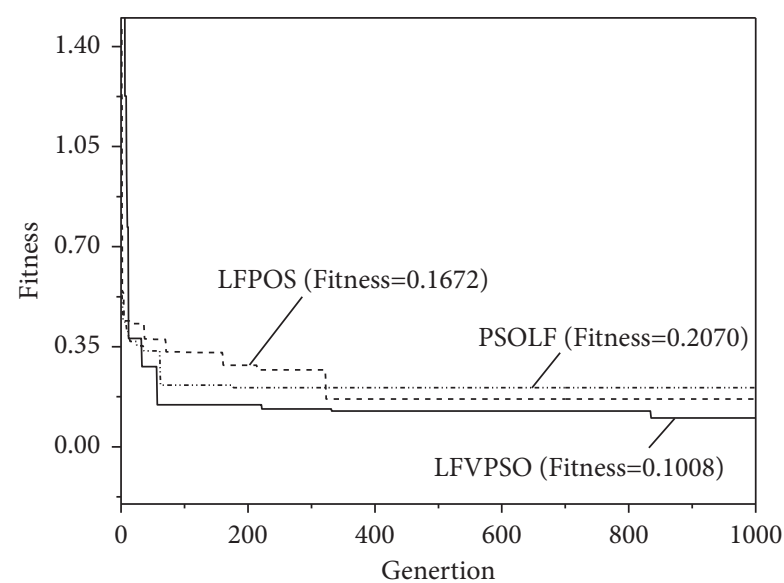

(b)

FIGURE 11: The convergence curves of fitness function for the modified BPNN with LFPSO [30], PSOLF [31], or LFVPSO algorithm: (a) flattype trench laying cable and (b) trefoil-type trench laying cable.

TABLE 9: The prediction and simulation results of maximum current capacity for different trench laying cables $\left(T_{\text {sur }}=283.15 \mathrm{~K}\right.$ and $\left.313.15 \mathrm{~K}\right)$.

\begin{tabular}{|c|c|c|c|c|c|c|c|c|}
\hline \multirow{2}{*}{ Cases } & \multirow{2}{*}{$\operatorname{Tsur}(\mathrm{K})$} & \multicolumn{6}{|c|}{ GA\&LFVPSO-BPNN } & \multirow{2}{*}{$\begin{array}{c}\text { COMSOL } \\
\left(T_{\max , i}\right) \max (\mathrm{K})\end{array}$} \\
\hline & & $I 1(\mathrm{~A})$ & $I 2(\mathrm{~A})$ & $I 3(\mathrm{~A})$ & $I 4(\mathrm{~A})$ & $I t, \max (\mathrm{A})$ & $\left(T_{\max , i}\right) \max (\mathrm{K})$ & \\
\hline \multicolumn{9}{|c|}{ Flat-type trench laying cable } \\
\hline 1 & 283.15 & 1111.22 & 1136.97 & 1093.90 & 1102.13 & 9427.61 & 363.15 & - \\
\hline 2 & 283.15 & 1110.86 & 1138.37 & 1092.23 & 1102.13 & 9426.28 & 363.15 & - \\
\hline 3 & 283.15 & 1111.16 & 1137.48 & 1093.26 & 1102.86 & 9428.76 & 363.15 & - \\
\hline Averaged & 283.15 & 1111.08 & 1137.61 & 1093.13 & 1102.37 & 9427.55 & 363.15 & 363.73 \\
\hline 1 & 313.15 & 892.48 & 905.78 & 877.03 & 875.87 & 7533.15 & 363.15 & - \\
\hline 2 & 313.15 & 893.95 & 905.64 & 876.60 & 874.77 & 7532.72 & 363.15 & - \\
\hline 3 & 313.15 & 894.37 & 903.90 & 876.00 & 875.95 & 7531.15 & 363.15 & - \\
\hline Averaged & 313.15 & 893.60 & 905.10 & 876.54 & 875.53 & 7532.32 & 363.15 & 363.00 \\
\hline \multicolumn{9}{|c|}{ Trefoil-type trench laying cable } \\
\hline 1 & 283.15 & 1043.16 & 1080.67 & 997.77 & 1012.59 & 8769.94 & 363.15 & - \\
\hline 2 & 283.15 & 1043.52 & 1080.57 & 998.08 & 1011.92 & 8769.73 & 363.15 & - \\
\hline 3 & 283.15 & 1044.68 & 1080.74 & 997.25 & 1011.61 & 8770.13 & 363.15 & - \\
\hline Averaged & 283.15 & 1043.78 & 1080.66 & 997.70 & 1012.04 & 8769.92 & 363.15 & 362.95 \\
\hline 1 & 313.15 & 848.16 & 852.47 & 813.57 & 833.91 & 7102.41 & 363.15 & - \\
\hline 2 & 313.15 & 847.29 & 852.94 & 812.61 & 833.79 & 7099.27 & 363.15 & - \\
\hline 3 & 313.15 & 848.20 & 852.45 & 813.55 & 833.93 & 7102.46 & 363.15 & - \\
\hline Averaged & 313.15 & 847.89 & 852.62 & 813.25 & 833.88 & 7101.42 & 363.15 & 363.32 \\
\hline
\end{tabular}




$$
\text { fitness }=\sum_{i}^{M}\left|\widehat{y}-\widehat{y}^{\prime}\right|_{i}^{2}
$$

where $\hat{y}$ is the normalized simulation value of training samples; $\hat{y}^{\prime}$ is the normalized prediction value of training samples; and $M$ is the number of training samples, $M=80$.

The maximum current capacity of trench laying cable $\left(I_{t, \text { max }}\right)$ is defined as follows:

$$
I_{t, \text { max }}=\operatorname{Max}\left(\sum_{1}^{4} 3 \frac{I_{i}}{\sqrt{2}}\right), \quad\left(T_{\max , i}\right)_{\max } \leq 363.15 \mathrm{~K},
$$

where $I_{i}$ is the single-cable current for loop $i$ and the currents of three cables in the same loop are kept the same and $T_{\max , i}$ is the cable maximum temperature of loop $i$ in the trench.

\section{Results and Discussion}

5.1. Temperature Prediction for Trench Laying Cable. The prediction and simulation results of cable maximum temperature for different loops in the trench (80 training samples for the flat-type trench laying cable model) are presented in Figure 9. It shows that the correlation coefficient $\left(R^{2}\right)$ between the prediction and simulation results of cable maximum temperature for different loops in the trench (flat-type trench laying cable model) is higher than 0.9990. Similarly, the prediction and simulation results of cable maximum temperature for different loops in the trench (80 training samples for the trefoil-type trench laying cable model) is presented in Figure 10. It shows that the correlation coefficient $\left(R^{2}\right)$ between the prediction and simulation results of cable maximum temperature for different loops in the trench (trefoil-type trench laying cable model) is higher than 0.9992. This means the temperature prediction network (LFVPSO-BPNN) for both flat-type and trefoil-type trench laying cable models trained in this study is reliable, which can successfully predict the cable maximum temperature of different loops in the trench. Meanwhile, five additional random test samples are also selected to verify the accuracy of the temperature prediction network (LFVPSO-BPNN). The prediction and simulation results of cable maximum temperature for different loops in the trench (5 random test samples for different trench laying cable models) are presented in Tables 7 and 8 . They shows that the predicted cable maximum temperatures for different loops $\left(T_{\max , i}\right)$ in the trench can agree well with those obtained by COMSOL Multiphysics, and the maximum deviation is less than $2 \mathrm{~K}$. This confirms that the LFVPSO-BPNN algorithm proposed in this study can accurately predict the cable maximum temperature for four-loop trench laying cables.

Based on the same training samples (Table 6) and same number of particle swarm (60), the convergence curves of fitness function for the modified BPNN with LFPSO [30], PSOLF [31] or LFVPSO algorithm are presented in Figure 11. It shows that, for the flat-type trench laying cable model, when the iteration reaches convergence, the computation times for the LFPSO-BPNN, PSOLF-BPNN, and LFVPSO-BPNN algorithm are $5651 \mathrm{~s}, 3801 \mathrm{~s}$, and $3977 \mathrm{~s}$, respectively, and their convergence values of fitness function are $0.2307,0.2223$, and 0.1005 , respectively. Similarly, for the trefoil-type trench laying cable model, when the iteration reaches convergence, the computation times for the LFPSOBPNN, PSOLF-BPNN, and LFVPSO-BPNN algorithm are 5918 s, 3977 s, and 4195 s, respectively, and their convergence values of fitness function are $0.1672,0.2070$, and 0.1008 , respectively. It is indicated that, under the same restrictions, as compared with LFPSO-BPNN algorithm, the computation time would be great reduced by using PSOLFBPNN and LFVPSO-BPNN algorithm. Meanwhile, as compared with LFPSO-BPNN and PSOLF-BPNN algorithm, the prediction accuracy would be further improved using LFVPSO-BPNN algorithm. Therefore, as compared with LFPSO-BPNN and PSOLF-BPNN algorithm, when LFVPSO-BPNN algorithm is used to predict the temperature of four-loop three-phase trench laying cables, its computation time would be reduced and the prediction accuracy would be improved as well.

\subsection{Prediction of Maximum Current Capacity for Trench} Laying Cable. The prediction and simulation results of maximum current capacity for different trench laying cables under different $T_{\text {sur }}$ are presented in Table 9. The air temperature on the ground $\left(T_{\text {sur }}\right)$ is set as $283.15 \mathrm{~K}$ and $313.15 \mathrm{~K}$, which represents moderate environment temperature and hot summer environment temperature, respectively. To reduce the prediction error of GA\&LFVPSO-BPNN algorithm, the cable current of each loop $\left(I_{i}\right)$ and the maximum current capacity of trench laying cable $\left(I_{t, \text { max }}\right)$ were calculated three times and averaged under different $T_{\text {sur }}$. Meanwhile, the $T_{\text {sur }}$ and $I_{i}$ predicted using GA\&LFVPSOBPNN algorithm are input into COMSOL Multiphysics, and the maximum value of the cable maximum temperature for different loops in the trench $\left(\left(T_{\max , i}\right)_{\max }\right)$ is computed and compared with the safe operating temperature of cable $(363.15 \mathrm{~K})$. As is shown in Table 9, for different cases, the maximum deviation between the simulation results of $\left(T_{\max , i}\right)_{\max }$ and safe operating temperature of cable $(363.15 \mathrm{~K})$ is $0.58 \mathrm{~K}$, which means the prediction results obtained using GA\&LFVPSO-BPNN algorithm should be reliable.

In Table 9, it also shows that, under different $T_{\text {sur }}$, when the current capacity of trench laying cable $\left(I_{t}\right)$ reaches its maximum value $\left(I_{t, \max }\right)$, the cable current of Loop $2\left(I_{2}\right)$ is the highest, and the cable currents of upper layer loops $\left(I_{1}\right.$, $I_{2}$ ) are higher than those of lower layer loops $\left(I_{3}, I_{4}\right)$. This may indicate that, for the case under $I_{t, \max }$, when both natural convection and radiation heat transfer are considered on the cable surfaces, the overall heat transfer on the cable surfaces of Loop 2 should be the best, and the heat transfer on the cable surfaces of upper layer loops should be better than that of lower layer loops. For the flat-type trench laying cable model, as $T_{\text {sur }}$ increases from $283.15 \mathrm{~K}$ to $313.15 \mathrm{~K}$, the maximum current capacity of trench laying cable $\left(I_{t, \text { max }}\right)$ decreases from $9427.55 \mathrm{~A}$ to $7532.32 \mathrm{~A}$, which decreases by 1895.23 A (20\%). Similarly, for the trefoil-type trench laying cable model, as $T_{\text {sur }}$ increases from $283.15 \mathrm{~K}$ to $313.15 \mathrm{~K}$, the maximum current capacity of trench laying 
cable $\left(I_{t, \max }\right)$ decreases from $8769.92 \mathrm{~A}$ to $7101.42 \mathrm{~A}$, which decreases by $1668.5 \mathrm{~A}(19 \%)$. This may indicate that when $T_{\text {sur }}$ increases from $283.15 \mathrm{~K}$ to $313.15 \mathrm{~K}$, the overall heat transfer of trench laying cable should be weakened, and its maximum current capacity $\left(I_{t, \max }\right)$ is decreased significantly. Furthermore, when air temperature on the ground $\left(T_{\text {sur }}\right)$ is fixed at $283.15 \mathrm{~K}$, as compared with the trefoil-type laying trench cable model, the $I_{t, \max }$ for the flat-type trench laying cable model can increase by 657.63 A (7.5\%). Similarly, when air temperature on the ground $\left(T_{\text {sur }}\right)$ is fixed at $313.15 \mathrm{~K}$, as compared with the trefoil-type laying trench cable model, the $I_{t, \max }$ for the flat-type trench laying cable model can increase by $430.9 \mathrm{~A}(6.1 \%)$. This means, under the same $T_{\text {sur }}$, the overall heat transfer performance for the flat-type trench laying cable should be better than that for the trefoil-type laying trench cable, and the maximum current capacity $\left(I_{t, \text { max }}\right)$ for the flat-type trench laying cable are obviously higher. Therefore, with the same working conditions, the flat-type laying method is recommended for the cable arrangement in the trench.

\section{Conclusion}

In this study, an adaptive optimized particle swarm optimization algorithm (LFVPSO) is proposed based on Levy flight algorithm, and it is used to modify the backpropagation neural network algorithm (LFVPSO-BPNN). Then combined with numerical simulations, a network algorithm for temperature prediction of trench laying cable is developed using LFVPSO-BPNN. Finally, the maximum current capacity of four-loop three-phase trench laying cable is calculated using LFVPSO-BPNN together with genetic algorithm (GA\&LFVPSO-BPNN). The main findings are as follows:

(1) The correlation coefficient between the prediction and simulation results of cable maximum temperature for different loops $\left(T_{\max , i}\right)$ in the trench is higher than 0.9990, and the maximum deviation of $T_{\max , i}$ is less than $2 \mathrm{~K}$. Therefore, the LFVPSO-BPNN algorithm proposed in this study can accurately predict $T_{\max , i}$ for four-loop trench laying cables. Furthermore, under the same restrictions, as compared with LFPSO-BPNN and PSOLF-BPNN algorithm, when LFVPSO-BPNN algorithm is used to predict the temperature of four-loop three-phase trench laying cable, its computation time would be reduced, and the prediction accuracy would be improved as well.

(2) The effect of ground air temperature $\left(T_{\text {sur }}\right)$ on the maximum current capacity of trench laying cable $\left(I_{t, \max }\right)$ is remarkable. When $T_{\text {sur }}$ increases from $283.15 \mathrm{~K}$ to $313.15 \mathrm{~K}$, the overall heat transfer of trench laying cable should be weakened, and its maximum current capacity $\left(I_{t, \max }\right)$ is decreased significantly. For the flat-type trench laying cable model, the $I_{t, \max }$ decreases from $9427.55 \mathrm{~A}$ to $7532.32 \mathrm{~A}$, which decreases by $20 \%$. And for the trefoil-type trench laying cable model, the $I_{t, \max }$ decreases from $8769.92 \mathrm{~A}$ to $7101.42 \mathrm{~A}$, which decreases by $19 \%$.

(3) Under the same ground air temperature $\left(T_{\text {sur }}\right)$, the overall heat transfer performance for the flat-type trench laying cable should be better than that for the trefoil-type laying trench cable, and the maximum current capacity $\left(I_{t, \max }\right)$ for the flat-type trench laying cable is obviously higher. When $T_{\text {sur }}$ is fixed at $283.15 \mathrm{~K}$, as compared with the trefoil-type laying trench cable model, the $I_{t, \max }$ for the flat-type trench laying cable model can increase by $7.5 \%$. Meanwhile, when $T_{\text {sur }}$ is fixed at $313.15 \mathrm{~K}$, as compared with the trefoil-type laying trench cable model, the $I_{t, \max }$ for the flat-type trench laying cable model can increase by $6.1 \%$.

These results would be meaningful for temperature rapid prediction and maximum current capacity calculation of trench laying cable. Furthermore, it should also be noticed that, the service life of a trench laying cable is closely related to the cable temperature. Therefore, as next step, the prediction work for the service life of a trench laying cable based on the predicted cable temperature should also be performed in the near future.

\section{Nomenclature}

$a_{1}$ : $\quad$ Scaling factor of velocity weight

$\underline{a}_{2}$ : $\quad$ Step scaling factor

A: $\quad$ Magnetic vector potential $(\mathrm{Wb} / \mathrm{m})$

$B: \quad$ Magnetic induction intensity $(\mathrm{T})$

$c_{p}: \quad$ Specific heat at constant pressure $(\mathrm{J} /(\mathrm{kg} \cdot \mathrm{K}))$

$C_{\varepsilon 1}$, Turbulence model parameters

$C_{\varepsilon 2}$ :

$\vec{E}: \quad$ Electric field strength (N/C)

$\vec{E}^{*}$ : $\quad$ Conjugate complex number of electric field strength

$f: \quad$ Electrical excitation frequency $(\mathrm{Hz})$

$g: \quad$ Gravitational acceleration $\left(\mathrm{m} / \mathrm{s}^{2}\right)$

$h_{1}$ : Convective heat transfer coefficient on the cable surface $\left(\mathrm{W} /\left(\mathrm{m}^{2} \cdot \mathrm{K}\right)\right)$

$h_{2}$ : Convective heat transfer coefficient on the concrete surface $\left(\mathrm{W} /\left(\mathrm{m}^{2} \cdot \mathrm{K}\right)\right)$

$h_{f}$. Equivalent heat transfer coefficient on the ground surface $\left(\mathrm{W} /\left(\mathrm{m}^{2} \cdot \mathrm{K}\right)\right)$

$\vec{H}_{;}$: Magnetic field strength $(\mathrm{A} / \mathrm{m})$

$H$ : $\quad$ Conjugate complex number of magnetic field strength

I: $\quad$ Cable current (A)

$I_{t, \text { max }}:$ Maximum current capacity (A)

$J: \quad$ Current density $\left(\mathrm{A} / \mathrm{m}^{2}\right)$

$J_{1}$ : $\quad$ Effective radiation on the cable surface $\left(\mathrm{W} / \mathrm{m}^{2}\right)$

$J_{2}: \quad$ Effective radiation on the concrete surface $\left(\mathrm{W} / \mathrm{m}^{2}\right)$

$k$ : $\quad$ Turbulent kinetic energy $\left(\mathrm{m}^{2} / \mathrm{s}^{2}\right)$

$\mathrm{Nu}_{\text {ave }}:$ Average Nusselt number

$p: \quad$ Pressure $(\mathrm{Pa})$

$P_{g}^{k}$ : Position of the particle with the best fitness in the previous particle swarm 
$P_{k}: \quad$ Shear production of turbulence $\left(\mathrm{kg} /\left(\mathrm{m} \cdot \mathrm{s}^{3}\right)\right)$

$P_{w}^{k}$ : Position of the particle with the worst fitness in the current particle swarm

$Q_{e}: \quad$ Total electromagnetic loss $\left(\mathrm{W} / \mathrm{m}^{3}\right.$ or $\left.\mathrm{W} / \mathrm{m}^{2}\right)$

$Q_{\mathrm{ml}}: \quad$ Magnetic loss $\left(\mathrm{W} / \mathrm{m}^{3}\right.$ or $\left.\mathrm{W} / \mathrm{m}^{2}\right)$

$Q_{\mathrm{rh}}: \quad$ Electrical loss $\left(\mathrm{W} / \mathrm{m}^{3}\right.$ or $\left.\mathrm{W} / \mathrm{m}^{2}\right)$

$r_{\mathrm{c}}$ : $\quad$ Cable core radius $(\mathrm{m})$

$r_{\mathrm{e}}: \quad$ External layer radius $(\mathrm{m})$

$r_{\text {ins }}: \quad$ Insulation layer radius $(\mathrm{m})$

$r_{\mathrm{s}}: \quad$ Sheath layer radius $(\mathrm{m})$

T: $\quad$ Temperature (K)

$T_{f}$. Air temperature in the trench $(\mathrm{K})$

$T_{\text {max }}$ : Cable maximum temperature $(\mathrm{K})$

$T_{\text {soil }}$ : Deep soil temperature (K)

$T_{\text {sur: }}$ Air temperature on the ground (K)

$\vec{v}: \quad$ Velocity vector $(\mathrm{m} / \mathrm{s})$

$V_{i}^{k+1}$ : Velocity of particle $i$ at iteration $k+1$

$W_{h}$ : Transitive relationship between the input layer and the hidden layer

$W_{o}$ : Transitive relationship between the hidden layer and the output layer

$x: \quad$ Input variable

$X_{i}^{k}$ : $\quad$ Position value of the particle $i$ at iteration $k$

$X_{i}^{k+1}$ : Position value of the particle $i$ at iteration $k+1$

$y$ : $\quad$ Output variable

$X: \quad$ The normalized simulation value of training samples

$\bar{y}^{\prime}$ : The normalized predicted value of training samples

\section{Greek letters}

$\beta$ : Volumetric expansion coefficient of air $\left(\mathrm{K}^{-1}\right)$

\section{Index of Levy distribution}

$\varepsilon:$ Turbulent dissipation rate $\left(\mathrm{m}^{2} / \mathrm{s}^{3}\right)$

$\varepsilon_{c}$ : Cable surface emissivity

$\varepsilon_{T}$ : Surface emissivity of the inner wall of the trench

$\lambda$ : Solid thermal conductivity $(\mathrm{W} /(\mathrm{m} \cdot \mathrm{K}))$

$\mu_{f}$ : Dynamic viscosity of air $(\mathrm{kg} /(\mathrm{m} \cdot \mathrm{s}))$

$\mu_{t}$ : Turbulent viscosity of air $(\mathrm{kg} /(\mathrm{m} \cdot \mathrm{s}))$

$\rho:$ Air density $\left(\mathrm{kg} / \mathrm{m}^{3}\right)$

$\sigma:$ Electrical conductivity $(\mathrm{S} / \mathrm{m})$

\section{Blackbody radiation constant}

$\begin{array}{ll}\sigma_{k}, \sigma_{t}, \sigma_{\varepsilon}: & \text { Turbulent Prandtl numbers } \\ \Phi: & \text { Heat flux }(\mathrm{W}) \\ \omega: & \text { Phase angle }\left({ }^{\circ}\right)\end{array}$

\section{Abbreviations}

BPNN: Backpropagation neural network

GA: Genetic algorithm

LFPSO: Modified particle swarm optimization algorithm combined with Levy flight algorithm
PSOLF: Enhanced particle swarm optimization algorithm combined with Levy flight algorithm

PVC: $\quad$ Polyvinyl chloride

XLPE: Cross-linked polyethylene.

\section{Data Availability}

The data used to support the findings of this study are included within the article.

\section{Conflicts of Interest}

The authors declare that there are no conflicts of interest regarding the publication of this study.

\section{Acknowledgments}

This work was supported by the Science and Technology Project (no. 52094019006Z) of State Grid Shanghai Electric Power Company.

\section{References}

[1] P. Ocłoń, M. Bittelli, P. Cisek et al., "The performance analysis of a new thermal backfill material for underground power cable system," Applied Thermal Engineering, vol. 108, pp. 233-250, 2016.

[2] B. Cong, X. Wu, and Z. Wang, "The economic and technical comparison for several power cables laying methods," High Voltage Engineering, vol. 27, no. 108, pp. 17-18, 2001.

[3] C. Fu, W. Si, L. Quan, and J. Yang, "Numerical study of convection and radiation heat transfer in pipe cable," Mathematical Problems in Engineering, vol. 2016, Article ID 5475136, 2018.

[4] IEC 60287-2-1: Electric Cables-Calculation of the Current Rating-Part 2-1: Thermal Resistance-Calculation of the Thermal Resistance, 2015.

[5] F. Jiang, "Status and prospect on calculation and increase of cable ampacity," Electric Wire and Cable, vol. 2020, no. 3, pp. 6-9, 2020.

[6] T. Matthew, P. Sujit, D. Francisco, and F. Alireza Vashghani, "Thermal analysis of cables in unfilled troughs: investigation of the IEC standard and a methodical approach for cable rating," IEEE Transactions on Power Delivery, vol. 27, no. 3, pp. 1423-1431, 2012.

[7] M. S. Al-Saud, M. A. El-Kady, and R. D. Findlay, "A new approach to underground cable performance assessment," Electric Power Systems Research, vol. 78, no. 5, pp. 907-918, 2008.

[8] L. Xiong, Y. Chen, Y. Jiao, J. Wang, and X. Hu, "Study on the effect of cable group laying mode on temperature field distribution and cable ampacity," Energies, vol. 12, no. 7, Article ID 3397, 2019.

[9] Y. Liu, N. Phan-Thien, R. Kemp, and X. Luo, "Coupled conduction-convection problem for an underground rectangular duct containing three insulated cables," Numerical Heat Transfer, Part A: Applications, vol. 31, no. 1, pp. 411-443, 1997.

\section{LFVPSO:}


[10] G. J. Anders, M. Coates, and M. Chaaban, "Ampacity calculations for cables in shallow troughs," IEEE Transactions on Power Delivery, vol. 25, no. 4, pp. 2064-2072, 2010.

[11] R. de Lieto Vollaro, L. Fontana, and A. Vallati, "Thermal analysis of underground electrical power cables buried in non-homogeneous soils," Applied Thermal Engineering, vol. 31, no. 5, pp. 772-778, 2011.

[12] P. Foteinopoulos, A. Papacharalampopoulos, and P. Stavropoulos, "On thermal modeling of additive manufacturing processes," CIRP Journal of Manufacturing Science and Technology, vol. 20, pp. 66-83, 2018.

[13] K. Salonitis, A. Stournaras, P. Stavropoulos, and G. Chryssolouris, "Thermal modelling of the material removal rate and surface roughness for die-sinking EDM," International Journal of Advanced Manufacturing Technology, vol. 40, no. 3-4, pp. 316-323, 2009.

[14] I. Marano, V. d'Alessandro, and N. Rinaldi, "Analytical modeling and numerical simulations of the thermal behavior of trench-isolated bipolar transistors," Solid-State Electronics, vol. 53, no. 3, pp. 297-307, 2009.

[15] P. Ocłoń, P. Cisek, M. Rerak et al., “Thermal performance optimization of the underground power cable system by using a modified Jaya algorithm," International Journal of Thermal Sciences, vol. 123, pp. 162-180, 2018.

[16] A. Cichy, B. Sakowicz, and M. Kaminski, "Economic optimization of an underground power cable installation," IEEE Transactions on Power Delivery, vol. 33, no. 4, pp. 1124-1133, 2018.

[17] W. Moutassem and G. J. Anders, "Configuration optimization of underground cables for best ampacity," IEEE Transactions on Power Delivery, vol. 25, no. 4, pp. 2037-2045, 2010.

[18] D. A. Zarchi, B. Vahidi, and M. M. Haji, "Optimal configuration of underground cables to maximise total ampacity considering current harmonics," IET Generation, Transmission \& Distribution, vol. 8, no. 6, pp. 1090-1097, 2014.

[19] D. Zarchi and B. Vahidi, "Hong point estimate method to analyze uncertainty in the underground cables temperature," Electrical Power and Energy Systems, vol. 124, Article ID 106390, 2021.

[20] C. Fu, W. Si, L. Quan, and J. Yang, "Numerical study of heat transfer in trefoil buried cable with fluidized thermal backfill and laying parameter optimization," Mathematical Problems in Engineering, vol. 2019, Article ID 4741871, 2019.

[21] S. S. Bu, J. Yang, M. Zhou, S. Y. Li, Q. W. Wang, and Z. X. Guo, "On contact point modifications for forced convective heat transfer analysis in a structured packed bed of spheres," Nuclear Engineering and Design, vol. 270, no. 5, pp. 21-33, 2014.

[22] Y. Jiao, Study on Temperature Field Distribution Simulation and On-Line Monitoring System of Power Cable, Chongqing University, Chongqing, China, 2018.

[23] P. Ocłoń, P. Cisek, M. Pilarczyk, and D. Taler, "Numerical simulation of heat dissipation processes in underground power cable system situated in thermal backfll and buried in a multilayered soil," Energy Conversion and Management, vol. 95, pp. 352-370, 2015.

[24] W. Si, C. Fu, X. T. Wu et al., "Numerical study of electromagnetic loss and heat transfer in an oil-immersed transformer," Mathematical Problems in Engineering, vol. 2020, Article ID 6514650, 2020.

[25] G. Kuznetsov and M. Sheremet, "Numerical simulation of turbulent natural convection in a rectangular enclosure having finite thickness walls," International Journal of Heat and Mass Transfer, vol. 53, no. 1-3, pp. 163-177, 2010.
[26] S. Liu, Y. Peng, Z. Xia et al., "The GA-BPNN-based evaluation of cultivated land quality in the PSR framework using Gaofen1 satellite data," Sensors, vol. 19, no. 23, Article ID 5127, 2019.

[27] F. Pan, H. Wen, X. Gao, H. Pu, and Z. Pang, "Clone detection based on BPNN and physical layer reputation for industrial wireless CPS," IEEE Transactions on Industrial Informatics, vol. 17, no. 5, pp. 3693-3702, 2020.

[28] X. Liu, Z. Liu, Z. Liang, and S. P. Zhu, "PSO-BP neural network based strain prediction of wind turbine blades," Materials, vol. 12, no. 12, Article ID 1889, 2019.

[29] C. Jin, S.-W. Jin, and L.-N. Qin, "Attribute selection method based on a hybrid BPNN and PSO algorithms," Applied Soft Computing, vol. 12, no. 8, pp. 2147-2155, 2012.

[30] H. Hüseyin and H. Uğuz, "A novel particle swarm optimization algorithm with Levy flight," Applied Soft Computing, vol. 23, pp. 333-345, 2014.

[31] R. Jensi and G. W. Jiji, "An enhanced particle swarm optimization with Levy flight for global optimization," Applied Soft Computing, vol. 43, pp. 248-261, 2016. 